Kaitlin J.H. Read, Leslie A. Melim, Ara S. Winter, and Diana E. Northup. Bacterial diversity in vadose cave pools: evidence for isolated ecosystems. Journal of Cave and Karst Studies, v. 83, no. 4, p. 163-188. DOI:10.4311/2020MB0120

\title{
BACTERIAL DIVERSITY IN VADOSE CAVE POOLS: EVIDENCE FOR ISOLATED ECOSYSTEMS
}

\author{
Kaitlin J.H. Read ${ }^{1,4}$, Leslie A. Melim², Ara S. Winter ${ }^{3}$, and Diana E. Northup ${ }^{1, C}$
}

\section{Abstract}

Microbial diversity of cave pools, especially vadose pools, has received relatively little attention. To help fill this gap, this study reports on the bacterial diversity of 17 pools in three New Mexican arid land caves: Carlsbad Cavern, Lechuguilla Cave, and Hell Below Cave. These pools are spread throughout the caves and, with two exceptions, are not connected. The pools share a basic water chemistry, with fresh water of the calcium-magnesium-bicarbonate type. These 17 pools have Chao1 values between 40 and 1738; the Shannon diversity averages $4.6 \pm 1.1$, ranging from 2.6 to 6.4 ; and the Simpson averages $0.881 \pm 0.099$, ranging from 0.622 to 0.981 . No two pools had the same communities, even at the phylum level. Nitrospirae, Alphaproteobacteria, Betaproteobacteria and Gammaproteobacteria were found $>5 \%$ abundance in nine or more cave pools. Actinobacteria, Chloroflexi, Fibrobacteres, Firmicutes and Plantomycetes were at $>5 \%$ in four to six pools. Of the top ten widespread bacterial genera, Nitrospira was found in all pools, with $>5 \%$ in eleven pools. Other common genera include Polyclorovans, Propionibacterium, Polaromonas, Haliangium, Bacillus, Subgroup 6 uncultured Acidobacteria, Candidatus Omnitrophica, and uncultured Nitrosomonadaceae. Presence of several potential nitrogen cycling bacteria (e.g., Nitrospira) in the study pools suggests that nitrogen cycling may be an important bacterial role. There is some evidence of human contamination, particularly in the heavily visited Big Room, Carlsbad Cavern, but it is not the dominant control. Rather than a single stable cave pool community, adapted to the cave pool ecosystem, the data show 17 different communities, despite relatively similar conditions. The data support the hypothesis that each pool is a unique, isolated ecosystem, with differences likely caused more by the isolation of each pool than by variable chemistry. Thus, the common habit of grouping samples, while useful for some questions, may not capture the diversity present in cave ecosystems.

\section{INTRODUCTION}

Karst caves, those found in limestone or dolomite, are recognized as potential windows into subsurface ecosystems (Engel, 2010). Microorganisms are an important part of these ecosystems, but understanding of their diversity is incomplete (Engel, 2010). The bacterial diversity of karst caves is a function of the physicochemical and nutrient setting, which varies widely between and within caves (e.g., Barton and Northup, 2007; Engel, 2010). These local conditions are, in turn, a function of the larger geological and ecological setting of the caves (Jones and Bennett, 2017; Brewer and Fierer, 2018; Alonso, et al., 2019). Because of interest in their unusual ecosystems, some of the best-studied caves are those with chemolithoautotrophy based on sulfur and/or methane (e.g., Movile Cave, Sarbu et al., 1996; Chen et al., 2009; Porter et al., 2009; Kumaresan et al., 2018; Cueva de Villa Luz, Hose et al., 2000; Hose and Rosales-Lagarde, 2017; Lower Kane Cave, Engel et al., 2004a, 2004b; Frasassi Cave, Macalady et al., 2006, 2007, 2008; Jones et al., 2016; and a semi-artificial mineral spring cave in Germany, Karwautz et al., 2018). Other caves also have ecosystems based on oxidation of iron and manganese, resulting in the formation of ferromanganese deposits (FMDs) (Northup et al., 2003; Spilde et al., 2005; Carmichael et al., 2013a, 2013b; Carmichael and Bräuer, 2015; Estes et al., 2017). The Nullarbor caves, Australia, have been shown to have a chemolithoautotrophic system based on nitrite oxidation (Holmes et al., 2001). The majority of karst caves, however, lack an obvious source of chemolithoautotrophy and are generally considered dependent on organic matter from the surface via water, air, or macrofauna transport (Goldscheider et al., 2006; Simon et al., 2007; Griebler and Lueders, 2009). However, karst caves in arid to semiarid regions are more isolated from surface inputs and are more likely to have chemolithoautotrophy (Ortiz et al., 2013, 2014).

Even with this limitation, karst caves are increasingly recognized as containing diverse microbial ecosystems. As a result, there are a growing number of studies in caves looking at the microbial communities on speleothems (Barton et al., 2007; Ikner et al., 2007; Legatzki et al., 2011, 2012; Engel et al., 2013; Yun et al., 2016a, Leuko et al., 2017, Thompson et al., 2019), wall rock (Porca et al., 2012; Carmichael et al., 2013a, 2013b; Carmichael and Bräuer, 2015; Wu et al., 2015; Lavoie et al., 2017; Sauro et al., 2018), cave sediment (Rusterholz and Mallory, 1994; Chelius and Moore, 2004; Adetutu et al., 2012; Wu et al., 2015; Brannen-Donnelly and Engel, 2015; Sauro et al., 2018; Thompson et al., 2019), and cave streams (Brannen-Donnelly and Engel, 2015; Plese et al., 2016). There are fewer studies on cave pools, which are

\footnotetext{
${ }^{1}$ Department of Biology, University of New Mexico

${ }^{2}$ Department of Earth, Atm. \& GIS, Western Illinois University

${ }^{3}$ Bosque Ecosystem Monitoring Program, Department of Biology, University of New Mexico

${ }^{c}$ Corresponding Author dnorthup@unm.edu

${ }^{4}$ Current address, Nanoscience and Microsystems Engineering, College of Engineering, University of New Mexico
} 
areas of standing water in caves (Shabarova and Pernthaler, 2010; Shabrova et al., 2013, 2014; Hershey et al., 2018; Sauro et al., 2018).

Studies of microorganisms in groundwater and cave streams have shown that the attached community is different from the planktonic community (Goldscheider et al., 2006; Brannen-Donnelly and Engel, 2015; Savio et al., 2018). A number of studies looking specifically at the planktonic community in karst aquifers through sampling of springs have identified an autochthonous microbial endokarst community (or AMEC) that is stable over time, particularly in aquifers with longer residence times (Farnleitner et al., 2005; Pronk et al., 2009; Savio et al., 2018). This community is disrupted during recharge with transient microorganisms from the surface, which then decrease over time (Savio et al., 2018, 2019; Wegner et al., 2019). Shabarova et al. (2013; 2014) looked at epiphreatic karst cave pools where seasonal rise of the water table completely flushed the pools. They found that each flood reintroduced the AMEC from the groundwater, which then rapidly lost diversity and abundance within weeks of residence time, such that the full AMEC was no longer present (Shabarova et al., 2013, 2014). The results from these AMEC studies suggest three possible microbial communities with different conditions: a surface community adapted to soil conditions, the AMEC adapted to groundwater conditions, and a cave pool community adapted to the conditions of the cave pool.

Cave pools in the vadose (unsaturated) zone are separate from the karst aquifer as they are perched above the water table. These pools collect infitrated water, often within days to weeks of rainfall events (Williams, 1983; Oster et al., 2012). However, based on oxygen isotopic and tritium studies (Even et al., 1986; Chapman et al., 1992; Turin and Plummer, 1995, 2001; Williams and Fowler, 2002), residence time for water in the vadose zone is generally much longer. In temperate climates, residence times range from <1 year up to several years (Spötl et al., 2005; Genty et al., 2014; Mischal et al., 2015). In arid climates, residence times are longer, up to several decades (Chapman et al., 1992; Turin and Plummer, 1995, 2001; Kaufman et al., 2003). Depth of the cave is also a factor, with shallow caves often having shorter residence times of weeks to months (Oster et al., 2012). One of the longest residence times (17-36 years) documented is for Carlsbad Cavern, which is both deep and in an arid climate (Chapman et al., 1992). Thus, water entering most karst caves is not usually from the current rain event, but rather from the rain infiltrating from the surface pushing water out into the cave from a reservoir of water in the vadose zone (Fairchild and Baker, 2012; Genty et al., 2014).

This idea of a reservoir within the vadose zone has implications for the microbial community entering the cave with the water. Particularly for caves where drip water has a long residence time within the vadose zone, the soil microbial community from the surface is unlikely to survive unchanged. Even within karst aquifers, the soil community does not persist (Savio et al., 2019; Wegner et al., 2019). Most studies of karst habitats have indeed found cave microbial communities as distinct from the surface communities (e.g., Engel, 2010; Ortiz et al., 2013; Lavoie et al., 2017). Cave pools, however, are almost unstudied. Data on the bacterial diversity of vadose pools is limited to one study that sampled the planktonic community in two deep ( $700 \mathrm{~m}$ below the entrance) vadose pools in a Swiss Alpine cave (Shabarova and Pernthaler, 2010). These two pools contained very diverse bacterial communities based on comparisons of the $16 \mathrm{~S}$ rRNA gene sequencing. These pools were dominated by Betaproteobacteria (Oxalobacteraceae), and Actinobacteria. One of the pools also had abundant Candidatus Omnitrophica (originally named OP3) (Rivas-Marı and Devos, 2018, Kirs et al., 2020). Out of 109 operational taxonomic units (OTUs) identified in the two pools, only five were shared (two affiliated with Oxalobacteraceae; one affiliated with Acinetobacter, one with Rhodoferax, and one with Nitrosomonadaceae). Shabarova and Pernthaler (2010) suggest the large differences between the two pools relatively close to each other is related to differences in chemistry, since one pool has higher $\mathrm{SO}_{4}{ }^{2-}$ and $\mathrm{Mg}^{2+}$, and possibly to different microbial inputs with incoming drips.

Thus, questions remain for the microbial diversity of cave pools, particularly vadose cave pools isolated from the local aquifer. This study reports on the diversity of planktonic bacteria from 17 vadose pools from three karst caves in the Guadalupe Mountains of New Mexico, including nine pools from Carlsbad Cavern, six pools in Lechuguilla Cave, and two pools from Hell Below Cave. This study uses this larger, more diverse dataset to better explore the suggestion raised by Shabarova et al. (2010) that vadose pools each contain unique communities.

\section{METHODS}

\section{Cave Setting and Geologic History}

The three karst caves sampled, Carlsbad Cavern, Lechuguilla Cave, and Hell Below Cave, are located in the Guadalupe Mountains of New Mexico and Texas, U.S.A., at the northern edge of the Chihuahuan Desert (Fig. 1). These caves are in the Upper Permian Capitan Reef Complex, mainly in the reef and forereef facies of the Capitan Limestone, but they also extend into the time-equivalent backreef facies of the Seven Rivers, Yates, and Tansill Formations (Hill, 1987; Jagnow, 1999). The backreef facies are dolomite with interbedded sandstones, while the reef and forereef are partly dolomitized limestone (Dunham, 1972; Jagnow, 1979; Melim and Scholle, 2002; Budd et al., 2013; Frost et al., 2013).

The caves of the Guadalupe Mountains are hypogene caves dissolved by reactions with rising waters producing $\mathrm{H}_{2} \mathrm{SO}_{4}$ at the water table (Hill, 1987; Jagnow et al., 2000; Engel et al., 2004; Hose and Macalady, 2006; Palmer, 2006, 


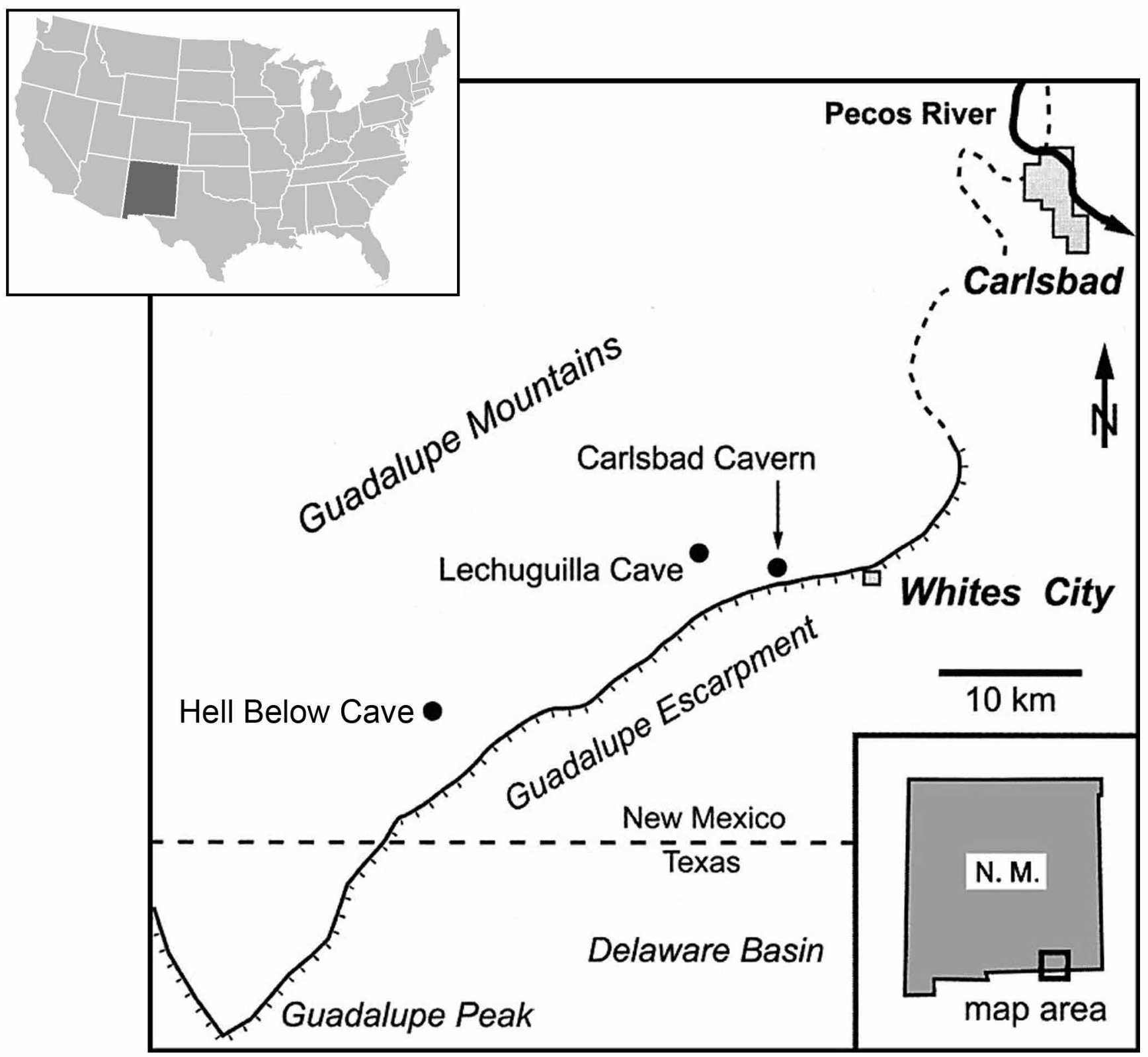

Figure 1. Location map of the three sampled caves, New Mexico, U.S.A. (After Palmer and Palmer, 2000).

2007; Kirkland, 2014). Speleogenesis started in the higher elevation caves (including Hell Below Cave) at $\sim 11.3 \mathrm{Ma}$ and continued during uplift through the upper reaches of Lechuguilla Cave at 6.0 to $5.7 \mathrm{Ma}$, and finally the lowest dated level, the Big Room in Carlsbad Cavern at 4.0 Ma to 3.9 Ma (Polyak et al., 1998). Since $\mathrm{H}_{2} \mathrm{SO}_{4}$ is a very strong acid, these karst caves contain unusually large rooms (such as the Big Room at over 3.3 hectares, 8.2 acres), often with flat floors that contain perched cave pools (Hill, 1987; Jagnow et al., 2000). Carlsbad Cavern and Lechuguilla Cave are very large and very deep caves ( $\sim 64 \mathrm{~km}$ long and $\sim 315 \mathrm{~m}$ deep; $\sim 242 \mathrm{~km}$ long and $\sim 484 \mathrm{~m}$ deep respectively, (Gulden 2020). Hell Below Cave is much smaller and more shallow ( $<400 \mathrm{~m}$ long; $\sim 60 \mathrm{~m}$ deep) than the other two caves.

The water table in the region is $\sim 960-970$ m elevation, well below the elevation of the sampled pools (Hill, 1990; Ingraham et al., 1990; Turin and Plummer, 2000; Land and Burger, 2008; Palmer and Palmer, 2012). Each pool is fed by ceiling drips and loses water by a combination of leaking and evaporation (Ingraham et al., 1990; Forbes, 2000; Turin and Plummer, 2000). With a few exceptions, the pools are not full to the spill point under current climate conditions, but show paleo-water lines that indicate wetter conditions in the past (Melim et al., 2006; Polyak et al., 2012). Dating of shelfstone in the Big Room, Carlsbad Cavern, suggests drying started by 13.5 ka during the transition from cool, wet glacial conditions to the warm, dry Holocene (Polyak et al., 2012). In the current arid climate, water infiltrates during infrequent heavy rains (Williams, 1983; Van der Heidje et al., 1997) and spends considerable time in the vadose zone. For Carlsbad Cavern, the residence time of water in the vadose zone is 17-36 years (Chapman et al., 1992), while for 
parts of Lechuguilla Cave it exceeds 50 years (Turin and Plummer, 1995, 2001; Turin et al., 2001). Considering the long residence times and the thin desert soils, the seepage water is expected to have very low TOC (Shen et al., 2015; Blyth et al., 2016; Lechleitner et al., 2017); which has been confirmed for seepage into Lechuguilla Cave (Turin and Plummer, 2000; Levy, 2007b).

Geochemical studies on pools in Lechuguilla Cave (Turin and Plummer, 2000; Levy, 2007a) and Carlsbad Cavern (Chapman et al., 1992; Forbes, 2000) have identified a 'typical pool water' that is fresh (Total dissolved solids, 200-500 $\mathrm{mg} / \mathrm{L}$ ) and of the calcium-magnesium-bicarbonate type, suggesting that leakage balances inflow, and evaporation is less important. Exceptions occur near gypsum deposits (where sulfate exceeds bicarbonate) and in a few pools with minimal leakage where evaporation has concentrated the water to a brine (Forbes, 2000; Turin and Plummer, 2000; Levy and Amrhein, 2011). However, there is considerable chemical variation among pools, even nearby pools, attributed to the complexity of infiltration, evaporation, and rock interaction for each pool (Forbes, 2000; Turin and Plummer, 2000; Levy, 2007a). Combining the chemical variation with the fact that pools do not currently connect via outflow suggests that these pools are completely isolated systems. How long they have been isolated is difficult to determine, but for some it could date back to the time when Big Room pools dried up at 13.5 ka during the terminal Pleistocene drought (Polyak et al., 2012).

Data on total organic carbon (TOC) and nitrate are available for drips and pools in Carlsbad Cavern (Brooke, 1996; Van der Heidje et al., 1997) and Lechuguilla (Turin and Plummer, 2000; Levy, 2007a, 2007b), albeit not for the specific pools sampled in this study. The highest TOC values $(20-40 \mathrm{mg} / \mathrm{L})$ were found in the eastern portions of Carlsbad and attributed to a combination of bat guano and a leaky sewage line (Brooke, 1996; Van der Heidje et al., 1997). Big Room and New Mexico Room pools have values between <1 (detection limit) and $15 \mathrm{mg} / \mathrm{L}$; Lower Cave pools are similar except for one pool with $18 \mathrm{mg} / \mathrm{L}$ (Van der Heidje et al., 1997). Higher values are near trails used by visitors and Van der Heidje et al., (1997) suggest trail maintenance, including washing, is the source of contamination. TOC values from Lechuguilla are uniformly low $(<1.7 \mathrm{mg} / \mathrm{L}$, with the exception of Briny Pool at $11 \mathrm{mg} / \mathrm{L}$; Turin and Plummer, 2000; Levy, 2007a, 2007b). Briny Pool is a very unusual pool that is highly concentrated by evaporation (Levy and Amrhein, 2011).

Nitrate values in Carlsbad are similar to TOC values: higher in eastern portions of the cave (36-238 mg/L), and low in the Big Room, New Mexico Room and Lower Cave (2-22 mg/L), except for one value of $30 \mathrm{mg} / \mathrm{L}$ from the Rookery (Brooke, 1996; Van der Heidje et al., 1997). Nitrate values collected by Turin and Plummer (2000) for Lechuguilla Cave are more variable, with $82 \%$ below $10 \mathrm{mg} / \mathrm{L}$ and $5 \%$ over $30 \mathrm{mg} / \mathrm{L}$. The average for the $95 \%$ of pools with $<30 \mathrm{mg} / \mathrm{L}$ is $6 \mathrm{mg} / \mathrm{L}$. Levy (2007a, 2007b) reported lower average values for Lechuguilla Cave (<1.7 mg/L).

\section{Sample Sites}

A total of 17 pools were analyzed including nine pools from Carlsbad Cavern, six pools in Lechuguilla Cave and two pools in Hell Below Cave. The diversity of sample sites is greater than suggested by just three caves as Carlsbad Cavern and Lechuguilla Cave are very large caves and the sample sites are widely spaced (Figs. 2 and 3).

Three rooms from Carlsbad Cavern were sampled, the Big Room, Lower Cave and the New Mexico Room (Fig. 2). These are all in Hydrologic Domain 2 of Van der Heidje et al., (1997), which they characterized as having diffuse infiltration with recharge in Bat Cave Draw and have no significant nitrate concentrations. The Big Room is over 3.3 ha and $\sim 200$ m beneath the surface (Hill, 1987). It is the most developed area in the cave with asphalt paved trails and $\sim 500,000$ visitors/year. It is also the most impacted historically with extensive off-trail damage dating back to private ownership (pre-1923). The floor is very irregular with abundant stalagmites and many pool basins (mostly dry). Four widely spaced pools were sampled in the Big Room: BR17, BR25, BR30 and BR44 (Fig. 2). Pool BR17 is 0.4 m deep pool and is located $\sim 3 \mathrm{~m}$ from the public trail (Fig. 4A). Although not visited today, the area around the pool was heavily trampled in the past and loose debris from the surrounding area covers the pool spar on the bottom of the pool. Pool BR25 is also $2-3 \mathrm{~m}$ from the public trail, but is separated from the trail by several large stalagmites. BR25 is currently $\sim 0.6 \mathrm{~m}$ deep, but has a well-developed shelfstone water line indicating a paleo depth $>2 \mathrm{~m}$. This area shows little evidence of past traffic. Pool BR30 is $<2 \mathrm{~m}$ from the public trail and is the only sampled Big Room pool that is nearly full (Fig. 4B). The maximum depth is $\sim 0.8 \mathrm{~m}$, which is $<5 \mathrm{~cm}$ from the overflow level. Pool BR44 is under the edge of Crystal Springs Dome, a rare (for Carlsbad) active stalagmite located adjacent to the public trail. The pool is currently up to $1 \mathrm{~m}$ in depth, but the paleo-water line suggests a maximum depth of $>2 \mathrm{~m}$ in the past. Although the closest of the Big Room pools to the public trail $(<1 \mathrm{~m})$, this pool sits under an overhang that protects it from direct contact. However, water entering the pool runs off of Crystal Springs Dome that is in reach of visitors.

Lower Cave sits underneath the Big Room at a depth of $\sim 240 \mathrm{~m}$ beneath the entrance (Hill, 1987). Visitation to Lower Cave is restricted to ranger-guided tours (12 person limit) on marked trails but not paved as in the Big Room. Three pools were sampled in Lower Cave: LC5, CC2-LC, and CC7-LC (Fig. 2). LC5 is in The Rookery, an area of active drips and many cave pearl nests (Hill, 1987; Melim and Spilde, 2018). This pool is $\sim 4 \mathrm{~cm}$ deep in a very flat area of the cave. The guided trail is immediately adjacent to this pool but is elevated on plastic platforms to keep visitors from walking in the water. Pool CC2-LC is the largest pool in Lower Cave ( 1 m deep), and the guided trail crosses it on a low bridge. 


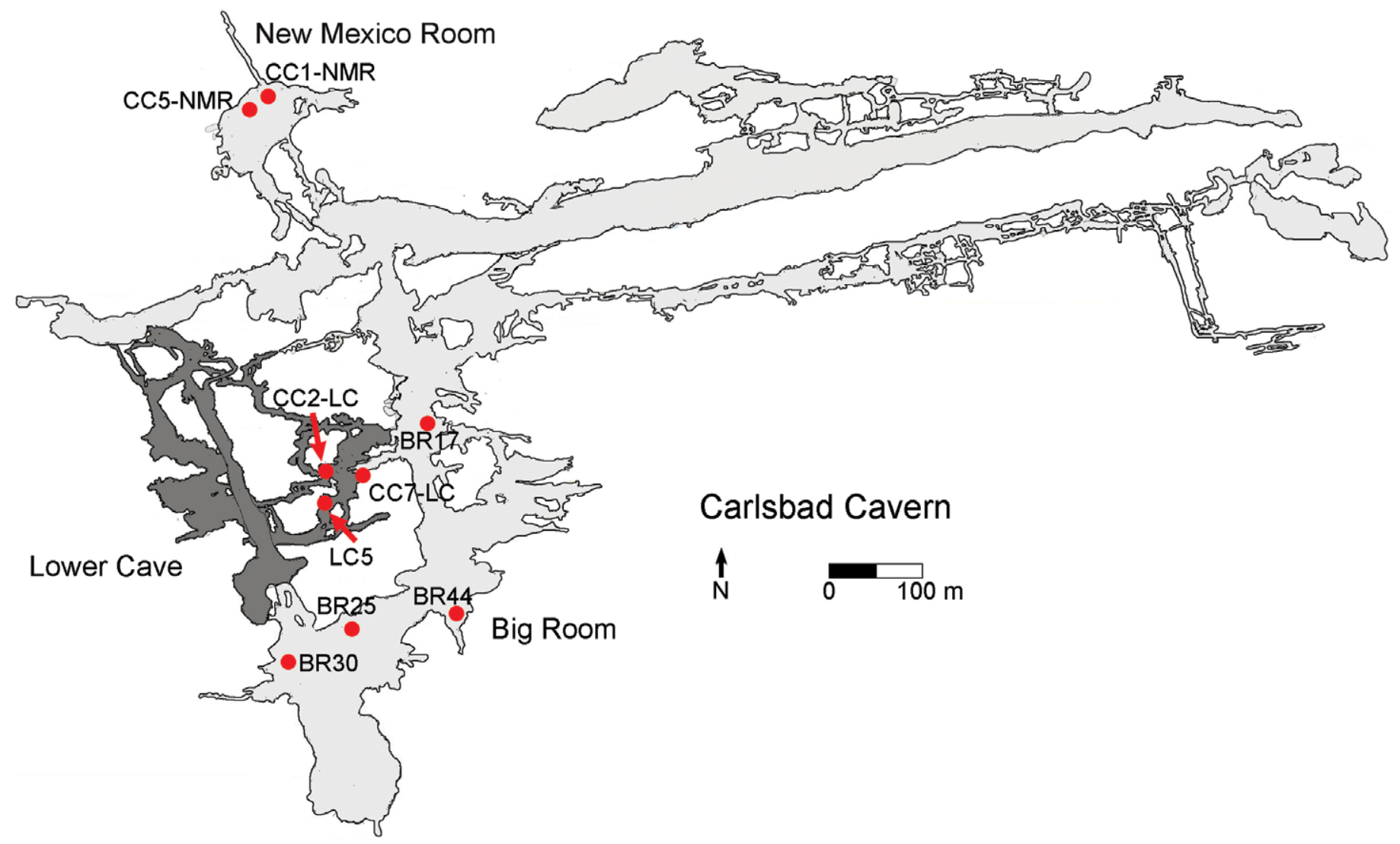

Figure 2. Map of Carlsbad Cavern showing the location of the sampled pools. Map courtesy of the Cave Research Foundation.

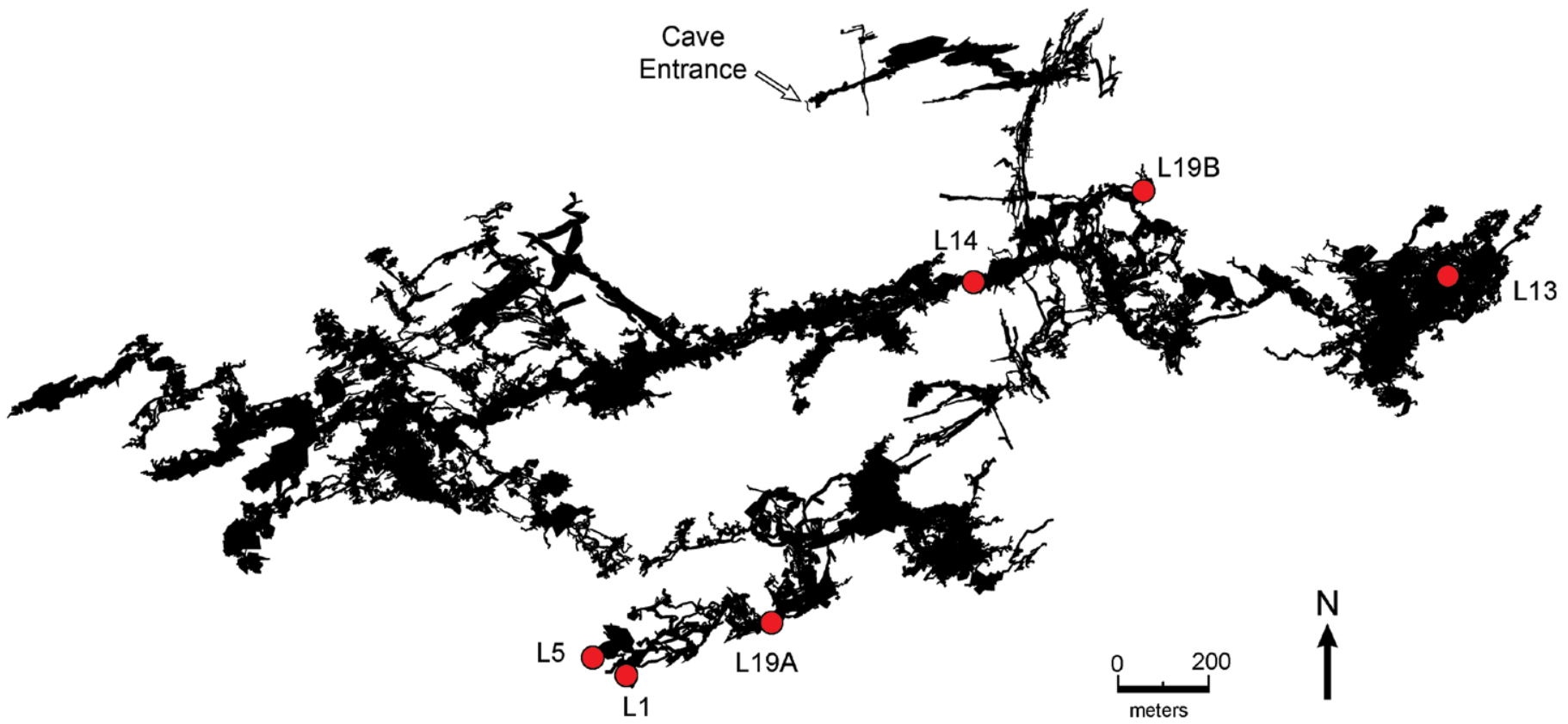

Figure 3. Map of Lechuguilla Cave showing the location of the sampled pools. Map courtesy of the National Park Service.

Like the nearby Rookery, this area has many active drips and the pool is full, or nearly so. CC7-LC, in contrast, is a small pool in an offshoot passage $\sim 50 \mathrm{~m}$ from the active trail in an area almost never visited.

The final sample area in Carlsbad Cavern is the New Mexico Room, an offshoot of the main cave at approximately the same elevation as the Big Room (Hill, 1987). It was never developed for visitors and is rarely visited today. Private visits were more common in the past, but never in large numbers like in the Big Room or Lower Cave. Two adjacent 

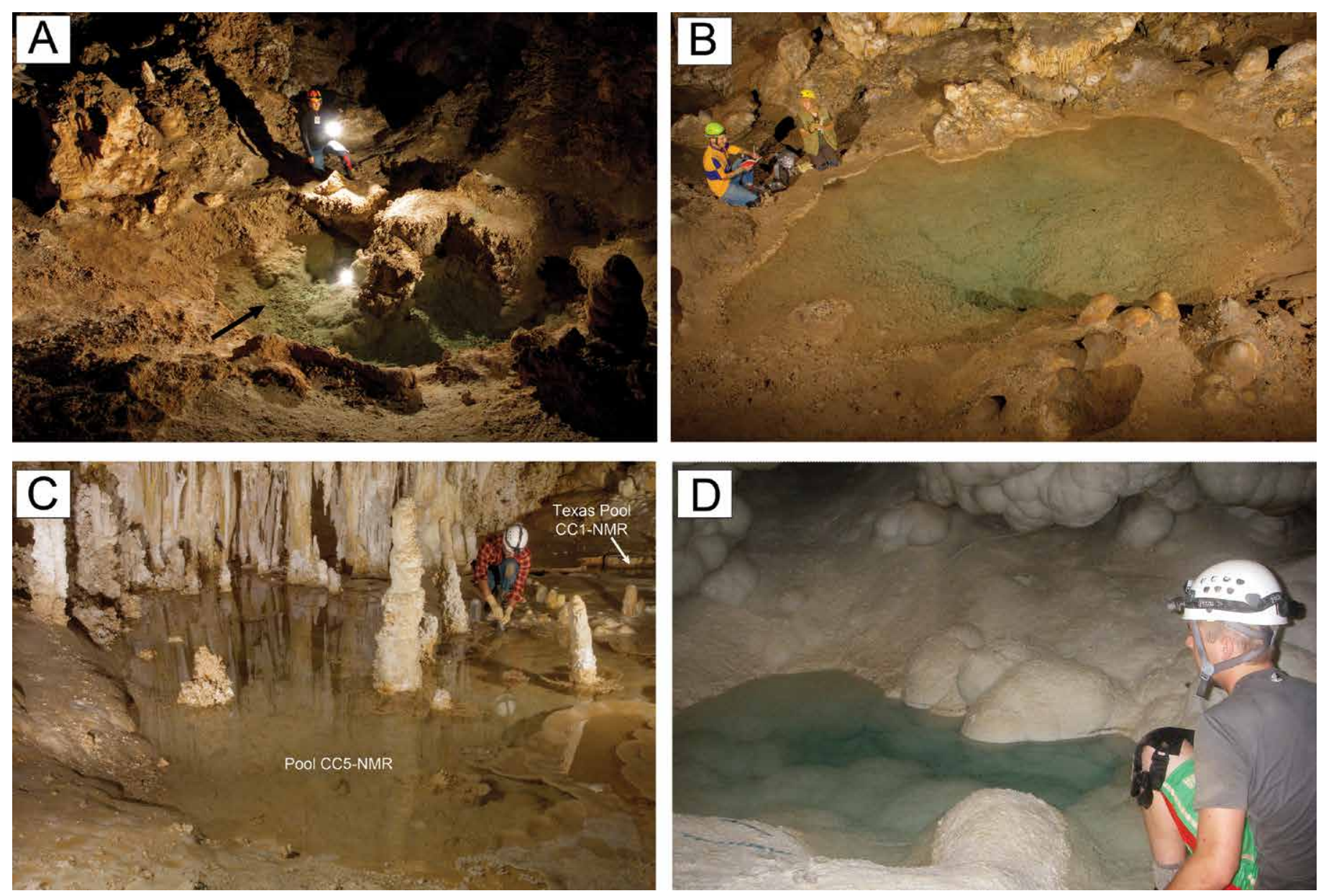

Figure 4. Representative cave pools in this study. A) Carlsbad Cavern, Big Room pool BR17. Photo taken from trail. Note loose debris in the bottom of the pool (arrow), which includes debris from the trail. B) Carlsbad Cavern, Big Room pool BR30, one of the few pools in Carlsbad that is nearly full. C) Carlsbad Cavern, New Mexico Room pools CC5-NMR and CC1-NMR. Note that CC5-NMR drains into CC1-NMR when it is full. D) Lechuguilla Cave pool L14. Photo credits: A-C, Kenneth Ingham; D, Pat Cicero.

pools were sampled, CC1-NMR and CC5-NMR (Figs. 2 and 4C). CC1-NMR is Texas Pool, a shallow ( 0.2 m) pool outlined in overhanging shelfstone, which defines a paleo-depth of $\sim 0.4 \mathrm{~m}$. CC5-NMR is a larger pool that is nearly full today. When it overflows, it drains into CC1-NMR. Currently, however, CC1-NMR only collects water from drips and flowstone. The marked trail goes by both pools.

Lechuguilla Cave is also located in the Carlsbad Caverns National Park, about $5.8 \mathrm{~km}$ northwest of Carlsbad Cavern (Fig. 1). Access to Lechuguilla Cave is limited by permit, with 50-100 research/exploration visitors per year for the whole cave. Six pools were sampled in Lechuguilla Cave (Fig. 3). Pool L1 is a drinking water source (so more visited than some) near an underground campsite. It is $17 \mathrm{~m} \times 14 \mathrm{~m}, \sim 12 \mathrm{~m}$ deep, and full. The pool is coated in pool spar and fed by several areas of flowstone on one side. Pool L5 is an irregular pool coated in yellowish pool spar, instead of the more common white, in the Vesuvius area of Lechuguilla Cave. It is shallow $(\sim 20 \mathrm{~cm})$ with maximum dimensions of $4 \mathrm{~m}$ $\times 6.5 \mathrm{~m}$ in a T-shape. The pool is full to the water line marked by minor areas of shelfstone. However, most of the pool edge is flowstone coming in from surrounding stalagmites. Pool L13 is $\sim 2 \mathrm{~m} \times 5 \mathrm{~m}$ and $\sim 1.5 \mathrm{~m}$ deep, but is the remnant of a larger pool up to $11 \mathrm{~m}$ deep. The larger pool is completely covered in pool spar and pool fingers. There is no evidence of a mineral water line at the current depth. Pool L14 is in the Deep Secrets area of Lechuguilla (Fig. 4D). The pool is a small $(2 \mathrm{~m} \times 4 \mathrm{~m},<0.5 \mathrm{~m}$ deep) remnant of a much larger pool ( $>3 \mathrm{~m}$ deep) coated in pool spar clouds. There is a faint mineral water line near the current water line, suggesting Pool L14 has been stable at this depth for some time. Pool L19A is a small $(0.5 \times 1 \mathrm{~m} ; \sim 10 \mathrm{~cm}$ deep) oval pool perched on a shelf in an area of continuous flowstone in the Tower Place area. The pool floor is coated in pool spar and the pool is full. L19B is a pool in the Nirvana area of Lechuguilla. No description is available for this pool.

Hell Below Cave is located in southeastern New Mexico in the Guadalupe Mountains, about $60 \mathrm{~km}$ southwest of the town of Carlsbad (Fig. 1). The two adjacent ( $<1 \mathrm{~m}$ apart) pools sampled are in an area with minimal visitation $(<10$ visitors/year), approximately $60 \mathrm{~m}$ below the surface. Hell Below pool HB1 is larger, much deeper (>2 m), and was near 
the spill level when sampled. HB2, in contrast, is small and shallow $(<10 \mathrm{~cm})$, was nearly full when sampled, and is fed by an active drip. HB2 likely drains into HB1 when full.

\section{Sampling and DNA Extraction}

Samples were collected under Permit \#CAVE-2008-SCl-0004 (Carlsbad Caverns National Park, 2008-2013), issued to Northup, and Forest Service Permit \#FS-2700-4 (10/09) (Hell Below Cave, 2011-2030) issued to Melim. Approximately one liter of water from pools was filtered through a sterile Sterivex syringe (Millipore, Billerica, MA) via a micropore $0.2 \mathrm{ul}$ filter, to capture microbial cells on the filter. Sucrose lysis buffer $(0.5 \mathrm{~mL})$ (Giovannoni et al., 1990) was added aseptically to break open cells and stabilize the DNA. Sterivex filters were capped with the syringe and a pipette tip and were then transported to the lab on ice where they were stored in a $-80^{\circ} \mathrm{C}$ freezer until DNA extraction. DNA released into the sucrose lysis buffer was extracted using MoBio Power Water DNA extraction kit using the manufacturer's protocol (MoBio, Carlsbad, CA) with bead beating instead of vortexing and elution in $30 \mu \mathrm{L}$ rather than $50 \mu \mathrm{L}$ of Buffer EB. Purified, extracted DNA was amplified with the polymerase chain reaction (PCR), using 46F (5'-GCYTAAYACATGCAAGTCG-3') as the forward primer and 1409R 5'-GTGACGGGCRGTGTGTRCAA-3') (Northup et al. 2010) as the reverse primer and AmpliTaq LD (Applied Biosystems) with an MJ thermal cycler as follows: 4 min denaturation at $94{ }^{\circ} \mathrm{C}$, followed by 35 cycles of $45 \mathrm{~s}$ annealing at $55^{\circ} \mathrm{C}, 2 \mathrm{~min}$ at $72{ }^{\circ} \mathrm{C}$ (extension), and $30 \mathrm{~s}$ at $94^{\circ} \mathrm{C}$ (denaturation), with a final $45 \mathrm{~s} 55^{\circ} \mathrm{C}$ annealing and 20 min $72{ }^{\circ} \mathrm{C}$ extension step after cycling was complete.

\section{Sequencing and Quality Control}

Samples were analyzed with next-generation sequencing of the 16S SSU gene bacterial V1-3 region (primer 27F, Lane, 1991) using Roche FLX and Titanium 454 technology conducted by MR DNA, Shallowater, TX (http://www.mrdnalab.com/). All 454 data were processed in QIIME 1.9.1 (Caporaso et al., 2010). Quality control and trimming of the 454 dataset were done using the split_libraries.py command with a lower length $(-L)$ of $100 \mathrm{bp}$ and an upper length $(-\mathrm{L})$ of 500. A quality score (-s) of 30 was chosen. Removal of erroneous sequences (denoising) and OTU clustering were done using pick_de_novo_otus.py pipeline with the sumaclust option (Mercier et al., 2013). The sumaclust algorithm is mainly useful to detect the 'erroneous' sequences created during amplification and sequencing protocols. OTUs were clustered at the $97 \%$ similarity level using sumaclust. The pick_de_novo command also picks the representative set and assigns taxonomy using uclust (Edgar, 2006) against the Silva 1.28 database (McDonald et al., 2012). Chimera checking was done using USEARCH to detect artifacts created during sequencing. Good's coverage showed that we were successful in getting nearly all of the diversity from our samples (Table 1). Values ranged from $87.13 \%$ to $99.11 \%$ with an average value of $94.98 \%$. Archaea were not analyzed.

\section{Taxonomic Analysis}

Bacterial taxonomies were assigned from the phylum to genera levels. OTUs unassigned to a phylogenetic level that passed chimera checking were consolidated into an Unassigned category. The ten most abundant bacterial phyla or Proteobacteria class by percentage were displayed; the remaining assigned phyla/proteobacterial classes were condensed into an Other category. The same method was used to categorize bacterial genera.

\section{Diversity Analysis}

Community dissimilarity was visualized using the phyloseq package (McMurdie and Holmes, 2013) and ggplot2 (Wickham, 2009) in R (R Development Core Team, 2012). Alpha diversity was analyzed using observed OTUs, Shannon, Simpson's Index of Diversity (1-D), and Chao1 indices in the phyloseq package. Alpha diversity measures were carried out on the raw data as recommended (McMurdie and Holmes, 2013). Observed OTUs and Simpson will scale with increasing library size; however both Chao1 and Shannon are robust measures of richness and diversity. Observed OTUs is the raw number of species OTUs present in each sample of quality controlled and clustered sequences as described above. Shannon index assumes even distribution of all OTUs, while Simpson's index is more influenced by dominated OTUs in a sample (Kim et al., 2017).

To assist in visualizing the diversity, plots and tables illustrate phyla and genera abundant in individual pools. Selection of which phyla (and genera) to illustrate is complicated by the large number present (38 phyla, 509 genera). Simply sorting by number of OTUs over-weighted the resulting lists for pools with large numbers of OTUs (mainly the Carlsbad Big Room pools). To better represent all pools, raw OTU counts were changed to Percent OTUs in each pool. Selecting only those phyla present at $>5 \%$ in any pool, 16 total phyla were plotted with less abundant phyla included as "other minor phyla" (0\% to $5 \%$ of total) (Fig. 5). In addition, these 16 phyla are also listed in Table 2, with the more abundant phyla for each pool noted. Table 3 shows the top ten genera across all pools, selecting for those genera present in the most pools. While useful, this table leaves $23 \%$ to $83 \%$ of the genera in the "other genera" category, and thus misses much of the diversity. Trying the top ten genera in each pool included 88 genera, too many to plot. The final genera plot with 25 genera (Fig. 6), includes only the top two genera in each pool (by percent abundance). Between $15 \%$ to $64 \%$ (average $35 \%$ ) of the genera in any single pool are not detailed, but included as "other minor genera." To more fully 




Figure 5. Top phyla/proteobacterial class distribution across pools in Carlsbad Cavern (Big Room and New Mexico Room-Lower Cave), Lechuguilla Cave, and Hell Below Cave.

Top Two Genera: All Pools
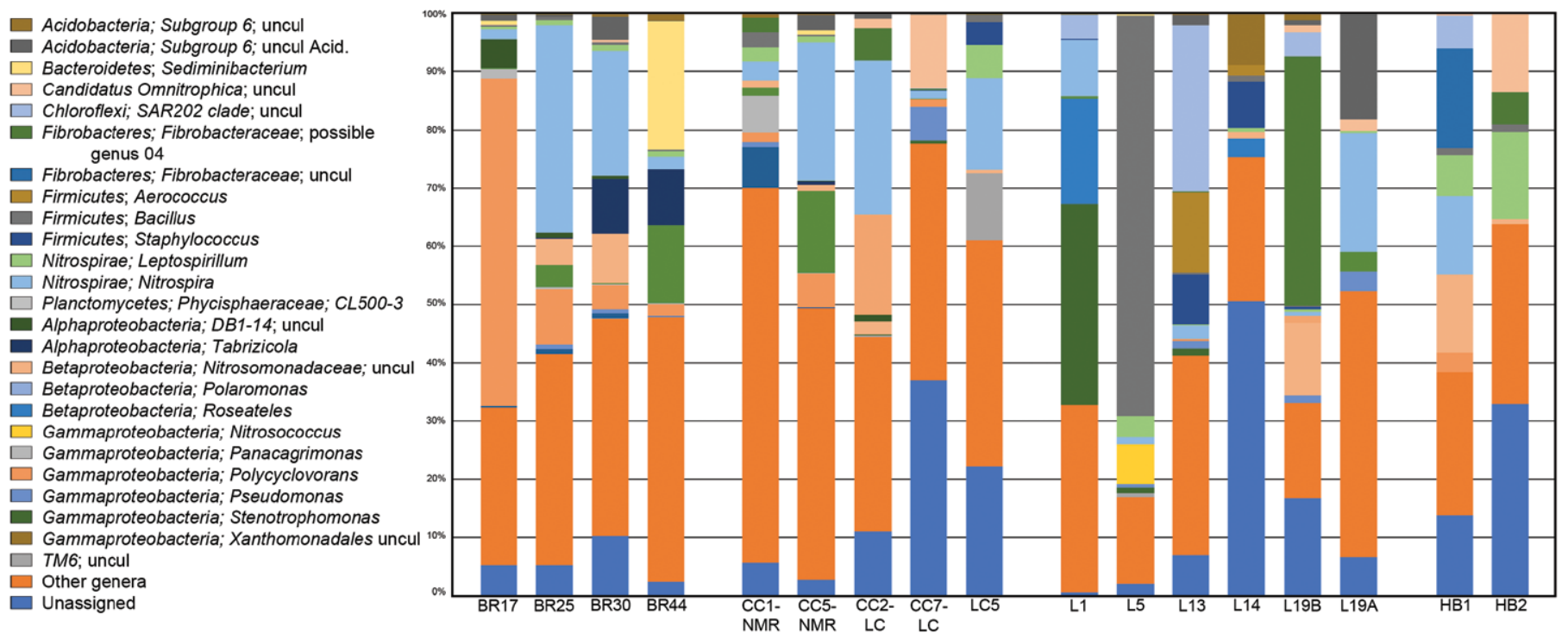

Figure 6. Distribution of the top two genera in pools in Carlsbad Cavern (Big Room and New Mexico Room-Lower Cave), Lechuguilla Cave, and Hell Below Cave.

illustrate the diversity at the genus level, all genera (total of 40 ) present at $5 \%$ or more in any pool are listed in Table 4. In addition, three pairs of pools were plotted showing all genera above two percent abundance. These include one relatively low-diversity pair (BR17 - L19A, Fig. 7), and two pairs of pools that are adjacent to each other (CC1-NMR CC5-NMR and HB1 - HB2; Figs. 8 and 9).

\section{RESULTS}

\section{Calculated Alpha Diversity of Pools}

Pools found in the Big Room of Carlsbad Cavern have the highest number of observed OTUs per pool, ranging from 231 to 925 (Table 1). The remaining pools all have a similar range of observed OTUs: pools in Carlsbad Cavern's Lower Cave and New Mexico Room have between 82 and 226; Hell Below Cave's two pools have 81 and 108, and Lechuguilla 


\section{Genera List: Low Diversity Pools BR17 vs. L19A}

Acidobacteria; Subgroup 6; uncul Acid

- Actinobacteria; Mycobacterium

- Armatimonadetes; Chthonomonadales; uncul

+Bacteroidetes; Cytophagaceae; uncul

- Candidatus Omnitrophica; uncul

Nitrospirae; Nitrospira

+Alphaproteobacteria; DB1-14; uncul

+Betaproteobacteria; Burkholderiales; Other

- Betaproteobacteria; Pelomonas

- Betaproteobacteria; Polaromonas

+Gammaproteobacteria; Cellvibrio

- Gammaproteobacteria; Escherichia-Shigella

+Gammaproteobacteria; Panacagrimonas

+Gammaproteobacteria; Polycyclovorans

- Gammaproteobacteria; Pseudomonas

- Gammaproteobacteria; Xanthomonadales Incertae Sedis; uncul

+Gammaproteobacteria; Other

Other minor genera

Unassigned

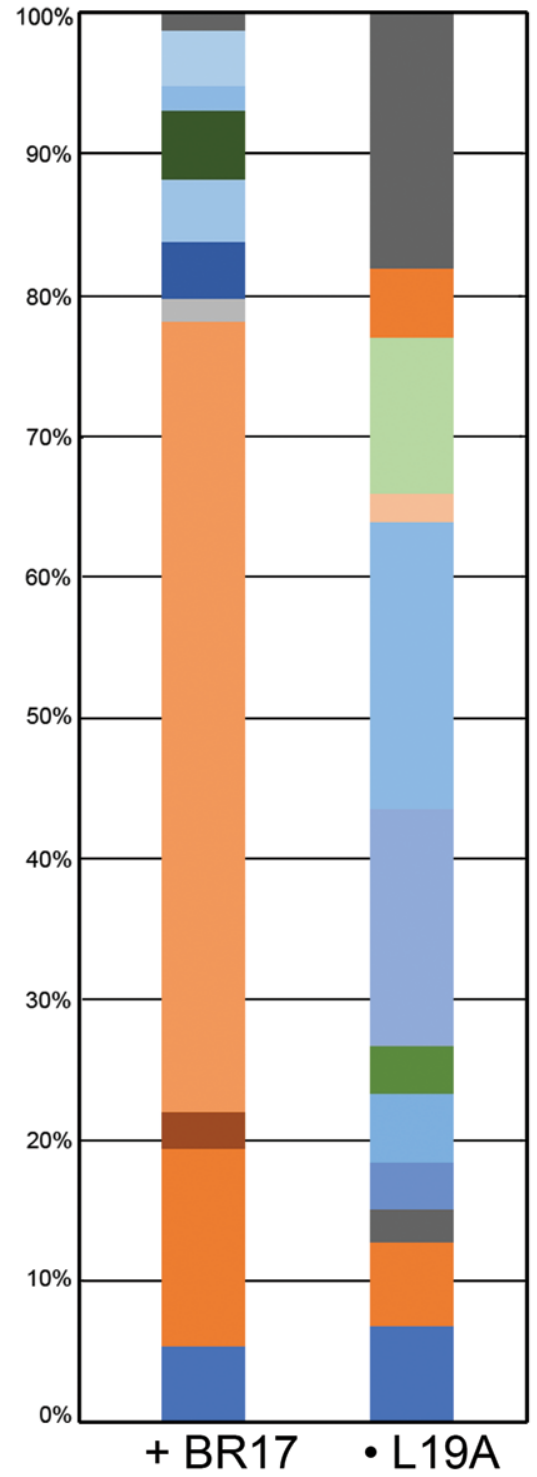

Figure 7. Comparison of genera at $>2 \%$ abundance in two relatively low diversity pools, BR17 (Simpson 0.677 ) and L19A (Simpson 0.881). Code: + genera present only in BR17; • genera present only in L19A.
Cave pools have the lowest value of 24 OTUs and range up to 151 . Chao1 diversity scales proportionally with observed OTUs (Table 1; Fig. 10). BR25 has both the highest number of OTUs and the highest Chao1 value (1738). Lechuguilla Cave pool L1 has the lowest number of observed species and the lowest Chao1 value (31).

Shannon diversity averages $4.6 \pm 1.1$ and ranges from 2.6 in pool L5, Lechuguilla Cave, to 6.4 in CC1-NMR, Carlsbad Cavern. Simpson averages $0.881 \pm 0.099$ and ranges from 0.622 in pool L5, Lechuguilla Cave. to 0.981 in CC1NMR, Carlsbad Cavern. Even though Simpson weighs abundant OTUs more, the two indices generally agree on the diversity (Table 1). No cave has exclusively high or low diversity values; all caves have Shannon and Simpson values that span the range of total diversity values. Lechuguilla pools are on average less diverse (Shannon of $3.7 \pm 0.9$; Simpson of $0.831 \pm 0.112)$ and include the two pools with lowest Shannon values (L1 and L5). The Big Room has higher diversity except for BR17 (Shannon of 3.5; Simpson of 0.677 ) that is dominated $(56 \%)$ by a single genus, Polyclorovans. Without BR17, the rest of the Big Room has Shannon values of $5.2 \pm 0.7$ and Simpson values of $0.913 \pm 0.036$. New Mexico Room and Lower Cave pools show slightly higher diversity values than the Big Room, with Shannon values of $5.3 \pm$ 0.9 and Simpson values of $0.941 \pm 0.042$. Hell Below Cave pools are slightly lower than the Big Room, with Shannon values of $4.8 \pm 0.7$ and Simpson values of $0.939 \pm 0.034$.

\section{Phylum Diversity}

Major differences in the bacterial phyla/proteobacterial classes can be seen within caves and between caves (Fig. 4, Table 2); no two pools have the same distribution of bacteria, even those adjacent to each other in a cave. Nitrospirae, Alpha-, Beta-, and Gammaproteobacteria are the only phyla/proteobacterial classes found $>5 \%$ abundance in nine or more cave pools. Actinobacteria, Chloroflexi, Fibrobacteres, Firmicutes, and Plantomycetes are at $>5 \%$ in $4-6$ pools. 
Table 1. Alpha diversity indices and Good's Coverage for the study pools.

\begin{tabular}{|c|c|c|c|c|c|c|}
\hline Study Pool & $\begin{array}{c}\text { Species } \\
\text { OTUs }\end{array}$ & Chao1 & Shannon & $\begin{array}{l}\text { Inverse } \\
\text { Simpson }\end{array}$ & $\begin{array}{c}\text { Good's } \\
\text { Coverage, \% }\end{array}$ & Unassigned, \% \\
\hline \multicolumn{7}{|c|}{ Carlsbad, Big Room } \\
\hline BR17 & 231 & 343 & 3.5 & 0.677 & 98.0 & 5 \\
\hline BR25 & 925 & 1738 & 5.3 & 0.885 & 97.6 & 5 \\
\hline BR30 & 680 & 1185 & 5.8 & 0.953 & 97.6 & 10 \\
\hline BR44 & 522 & 1065 & 4.5 & 0.899 & 97.4 & 2 \\
\hline \multicolumn{7}{|c|}{$\begin{array}{c}\text { Carlsbad Cavern, New Mexico Room \& } \\
\text { Lower Cave }\end{array}$} \\
\hline CC1-NMR & 236 & 335 & 6.4 & 0.981 & 98.7 & 6 \\
\hline CC5-NMR & 151 & 278 & 4.7 & 0.907 & 97.0 & 3 \\
\hline CC2-LC & 113 & 141 & 4.5 & 0.888 & 98.6 & 11 \\
\hline CC7-LC & 170 & 213 & 6.0 & 0.976 & 98.7 & 37 \\
\hline LC5 & 82 & 231 & 4.9 & 0.953 & 98.8 & 22 \\
\hline \multicolumn{7}{|l|}{ Lechuguilla Cave } \\
\hline L1 & 24 & 31 & 2.9 & 0.809 & 99.3 & 1 \\
\hline L5 & 89 & 171 & 2.6 & 0.622 & 99.3 & 2 \\
\hline L13 & 71 & 88 & 5.0 & 0.945 & 96.9 & 7 \\
\hline L14 & 102 & 250 & 4.0 & 0.886 & 99.4 & 51 \\
\hline L19B & 151 & 249 & 4.3 & 0.842 & 99.0 & 17 \\
\hline L19A & 33 & 40 & 3.5 & 0.881 & 99.7 & 7 \\
\hline \multicolumn{7}{|l|}{ Hell Below Cave } \\
\hline HB1 & 81 & 147 & 4.4 & 0.916 & 98.0 & 14 \\
\hline HB2 & 108 & 166 & 5.3 & 0.963 & 99.4 & 33 \\
\hline
\end{tabular}

Acidobacteria, Armatimonadetes, Bacteroidetes, Candidatus Omnitrophica, Deltaproteobacteria, TM6, and Verrucomicrobia are found in less than four pools at $>5 \%$ abundance.

The most common phylum is Proteobacteria, which is common in karst caves and often dominant (Tomczyk-Żak and Zielenkiewicz, 2016). Beta- and Gammaproteobacteria are the most widespread. Betaproteobacteria show up in all pools except L5 in Lechuguilla Cave and vary from $2 \%$ to $22 \%$. All pools have Gammaproteobacteria, which is the second highest phylum/class overall with $66 \%$ in BR17, and varies across all pools from $2 \%$ to $66 \%$, but with generally higher percentages in Carlsbad Cavern pools (Table 2). In six pools, Gammaproteobacteria are either the most abundant (BR17, CC1-NMR, L1) or the second most abundant (BR25, LC5, L5). Alphaproteobacteria are low in Lechuguilla Cave and Hell Below Cave pools (0-5\%, absent in two), and more dominant in Carlsbad Cavern pools (2-25\%, with four pools over $11 \%$ ). Deltaproteobacteria are present across all pools, but only three pools have more than $5 \%$.

The bacterial phylum Nitrospirae is also noted as common in karst caves (Tomczyk-Żak and Zielenkiewicz, 2016), but not usually in the abundance found in these cave pools. Nitrospirae is widespread, being found in every pool water sample, but varying from $<1 \%$ to $36 \%$. It is the most abundant phylum in eight pools. The highest percentage of Nitrospirae was observed in Carlsbad Cavern's BR25 (36\%) and it is $>20 \%$ in six pools, and $>10 \%$ in two pools (Table 2 ).

Of the five phyla found in 4-6 pools at $>5 \%$, Actinobacteria, Chloroflexi, and Firmicutes, and Plantomycetes are also found in some caves worldwide, but Fibrobacteres is rare (Tomczyk-Żak and Zielenkiewicz, 2016). Actinobacteria is noted as abundant in caves, second only to Proteobacteria, but most commonly on surfaces (Tomczyk-Żak and Zielenkiewicz, 2016). Actinobacteria is present in 11 pools at $>1 \%$, but at $<5 \%$ in five of those. In the other six, it ranges from $7 \%$ to $22 \%$ (Table 2). Actinobacteria is not the dominant phylum in any pool. Chloroflexi are minor constituents in several pools ( $1 \%$ to $7 \%$, Table 2), except in Lechuguilla Cave pool L13, where it is the dominant phylum at $28 \%$ abundance. However, five of the nine Carlsbad Cavern pools had no Chloroflexi, nor did one Lechuguilla pool and one Hell Below pool. Firmicutes, another phylum commonly found in caves (Tomczyk-Żak and Zielenkiewicz, 2016), showed the highest percentage, $69 \%$ in Lechuguilla pool L5 (Vesuvius), of any phylum observed in any pool (Table 2). In addi- 


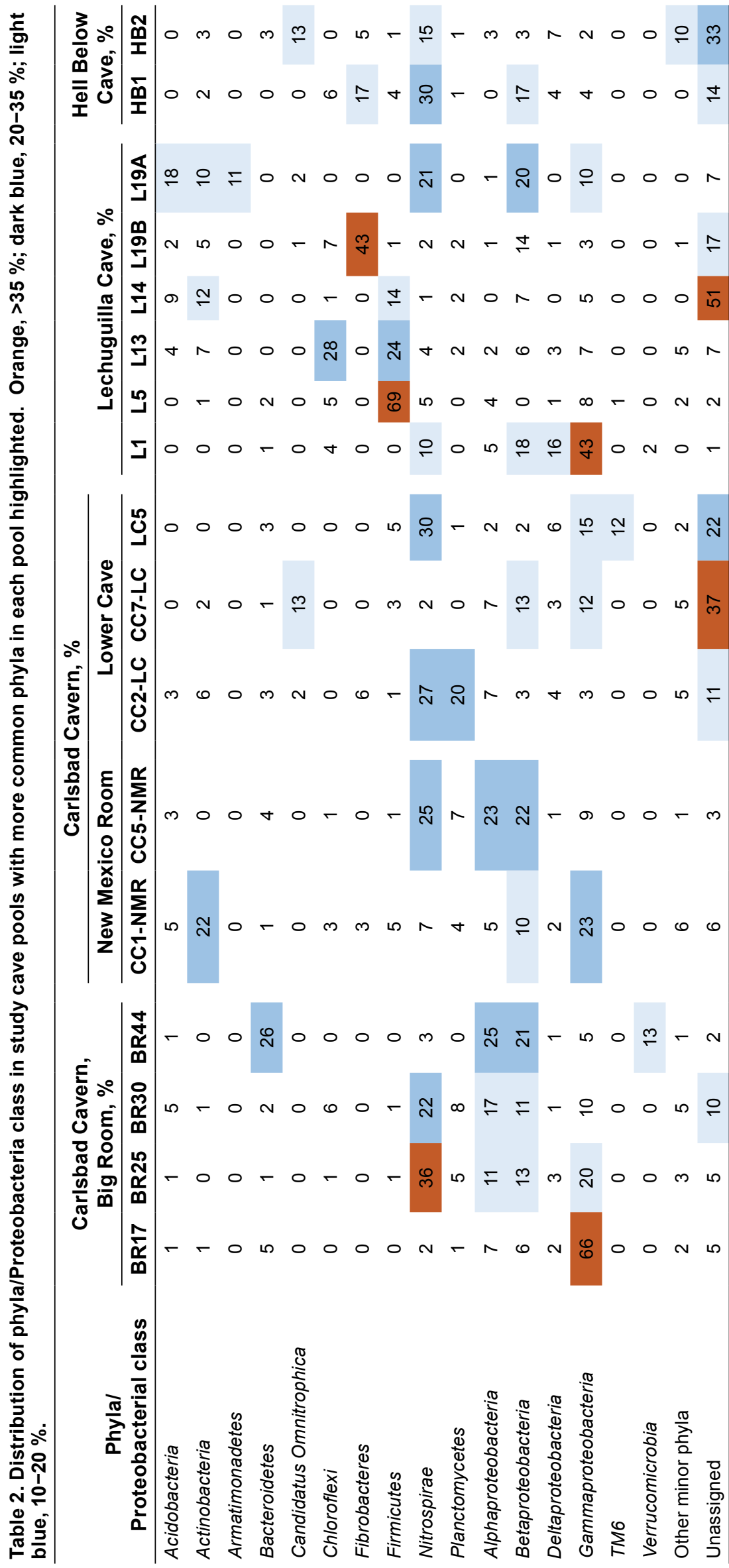

tion, Firmicutes are abundant in two other Lechuguilla pools (L13 at $24 \%$ and L14 at $14 \%)$. Elsewhere, Firmicutes are absent in four pools (BR17, BR44, L1, and L19A) and present at $1 \%$ to $5 \%$ in the remaining pools. Planctomycetes is absent to low (0 $\%$ to $2 \%$ ) in Lechuguilla Cave and Hell Below Cave pools and four Carlsbad Cavern pools, but are more present (4\% to $8 \%$ ) in the four other Carlsbad pools, reaching, $20 \%$ in CC2-LC in Lower Cave. The Fibrobacteres phylum is absent from 12 pools across all three caves, present but minor (3\% to $6 \%)$ in two Carlsbad Cavern pools and one Hell Below pool, but high in two pools (43\% in Lechuguilla Cave pool L19B and $17 \%$ in Hell Below Cave pool HB1).

Acidobacteria, Bacteroidetes and Verrucomicrobia are widespread in caves (Tomczyk-Żak and Zielenkiewicz, 2016), but less so in the study cave pools (Table 2). Acidobacteria are present in 10 pools but at low levels ( $<5 \%)$ except in two Lechuguilla Cave pools (18\% in L19A and $9 \%$ in L14). Bacteroidetes is the most abundant phylum in one Carlsbad Cavern pool, with $26 \%$ abundance in BR44. Other pools in Carlsbad Cavern contained $1 \%$ to $5 \%$ abundance of Bacteroidetes. Four of the six Lechuguilla Cave pools and one Hell Below Cave pool contained no Bacteroidetes. The other three pools in these two caves contained $1 \%$ to $3 \%$ Bacteroidetes. Verrucomicrobia is only found in two pools (at a relative abundance greater than $1 \%$ ), but makes up $13 \%$ of the microbiota in BR44.

Bacterial phyla Armatimonadetes, Candidatus Omnitrophica, and TM6 are not known from many caves (Tomczyk-Żak and Zielenkiewicz, 2016), but each is found at $>10 \%$ in one or two pools. Armatimonadetes is $11 \%$ in L19A; Candidatus Omnitrophica is $13 \%$ in CC7-LC and $13 \%$ in HB2; TM6 is $12 \%$ in L5 (Table 2). Other minor phyla (Table 2) include phyla present at $<5 \%$ in any pool. Five of those are present at 2-5\% including Cyanobacteria, Gemmatimonadetes, Saccharibactia, SM2F11, and Other Proteobacteria.

\section{Genera Diversity}

Of the top 10 most widespread bacterial genera present within these phyla/proteobacterial classes (Table 3), none were 


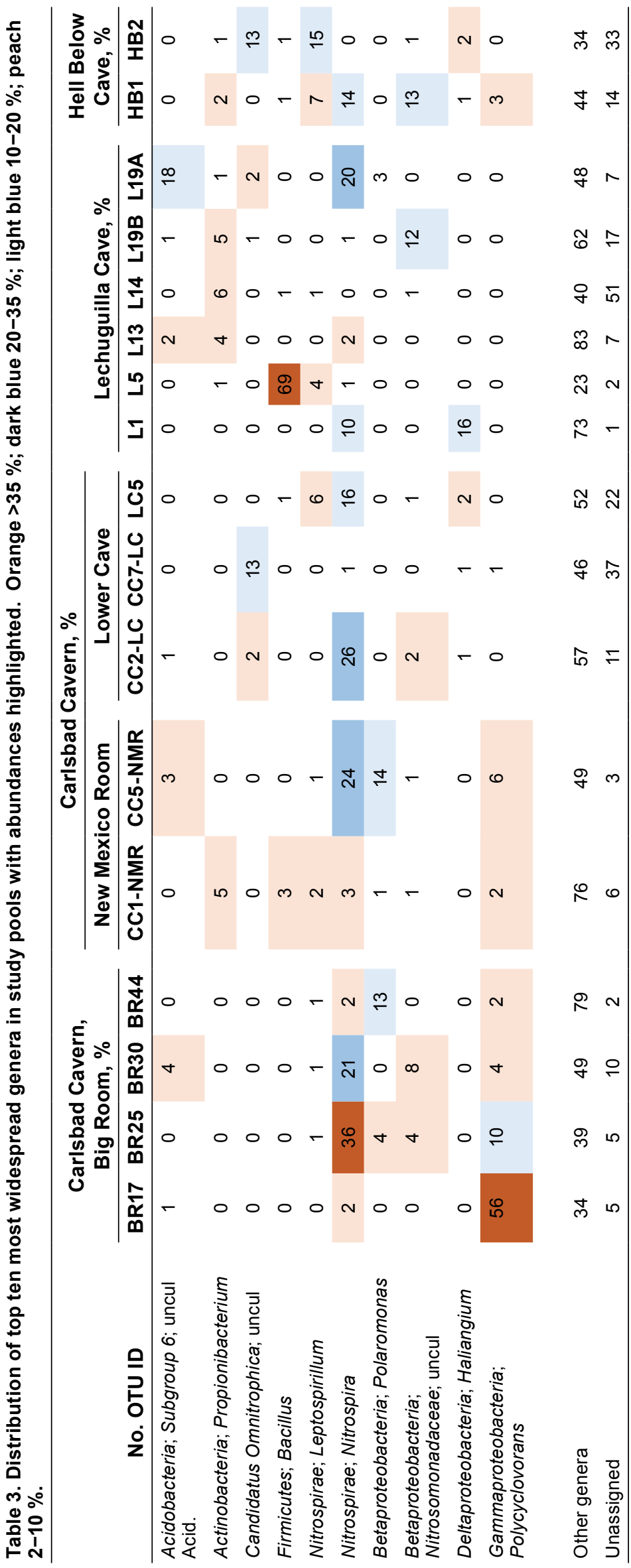

found in all pools. The most widespread was Nitrospira, a genus classified to the Nitrospirae phylum that was present in eight pools at $>10 \%$ (and most abundant in six of those eight, Table 4) and present above $2 \%$ in four more. Leptospirillum, another genus in the Nitrospirae phylum, was present $>2 \%$ in five pools, including two pools that lack Nitrospira. The Gammaproteobacteria Polyclorovans was the second most widespread genus, found in six of the Carlsbad pools and one pool in Hell Below Cave. In Carlsbad Cavern pool BR17, Polyclorovans was $56 \%$ of the OTUs. Other widespread genera include the Actinobacteria Propionibacterium (five pools, $2 \%$ to $6 \%$ ); Betaproteobacteria Polaromonas (4 pools, $3 \%$ to 14 $\%$ ); and Deltaproteobacteria Haliangium (3 pools, $2 \%$ to $16 \%$ ). Bacillus, a genus in Firmicutes was found in only two pools over $2 \%$, but one of those (Lechuguilla Cave pool L5) had $69 \%$, the highest abundance of any genus in this study. Completing the list of the top 10 are three uncultured genera: Acidobacteria, Subgroup 6; uncultured Acidobacteria bacterium (four pools, $2 \%$ to $18 \%$ ); Candidatus Omnitrophica, uncultured bacteria (four pools, $2 \%$ to $13 \%$ ); and Betaproteobacteria Nitrosomonadaceae, uncultured (five pools, $2 \%$ to $13 \%$ ).

Table 4 lists all genera present at $\geq 5 \%$ in any pool, which is 40 genera for only 17 pools. 28 of these 40 genera $(70 \%)$ were only present in one pool at $\geq 5$ $\%$. Only six of these 40 genera were present at $\geq 5$ $\%$ in three or more pools, one of which, Nitrospira, was present in eight pools. Nitrospira was also the most abundant genus in six pools (five in Carlsbad Cavern: BR25, BR30, CC5-NMR, CC2-L2, LC5, and one in Lechuguilla Cave: L19A). Each of the other 11 pools had a different most abundant genus (Table 4), including four already noted above in the top 10 most widespread genera (Carlsbad Cavern pool CC7-LC, Candidatus Omnitrophica, uncultured bacteria; Lechuguilla Cave pool L5, Bacillus; Hell Below Cave pool HB2, Leptospirillum; and Carlsbad Cavern pool BR17, Polyclorovans). Two Lechuguilla Cave pools (L13, Chloroflexi; SAR202 clade; uncultured and L19B, Fibrobacteres; Fibrobacteraceae; possible genus 04 ) have top genera also found in other pools at $\geq 5 \%$, but in the other five pools (Carlsbad Cavern pools BR44 and CC1-NMR, and Lechuguilla Cave pools L1, L5, and L15) the most abundant genus in the pool was only found at $\geq 5 \%$ in that one pool.

Since five pools have top genera found in only one pool at $>2 \%$, a bar plot of the top two genera in each pool was done to include all of the top genera (total 25 genera; Fig. 5). Genera not included ("Other genera") range from $15 \%$ (in Lechuguilla Cave pool L5, which has $69 \%$ Bacillus) to $64 \%$ (in Carlsbad Cavern pool CC1-NMR, the most diverse pool (Table 1)). Pools with $>10 \%$ unassigned OTUs included 
Table 4. List of genera present at $\geq 5 \%$ in any pool. Also listed are the number of pools each is found in at that level and which (if any) pools the genus in the most abundant genus.

\begin{tabular}{|c|c|c|}
\hline OTU, Genus & $\begin{array}{c}\text { No. of pools } \\
>5 \%\end{array}$ & Most abundant genus in pool(s) \\
\hline Acidobacteria; Subgroup 6; uncul Acid & 1 & $\cdots$ \\
\hline Acidobacteria; Subgroup 6; uncul & 1 & L14 \\
\hline Actinobacteria; Propionibacterium & 3 & $\cdots$ \\
\hline Armatimonadetes; Chthonomonadales; uncul & 1 & $\cdots$ \\
\hline Bacteroidetes; Sediminibacterium & 1 & BR44 \\
\hline Candidatus Omnitrophica; uncul & 2 & CC7-LC \\
\hline Chloroflexi; AKIW781; uncul & 1 & $\cdots$ \\
\hline Chloroflexi; SAR202 clade; uncul & 2 & L13 \\
\hline Fibrobacteres; Fibrobacteraceae; possible genus 04 & 3 & L19B \\
\hline Fibrobacteres; Fibrobacteraceae; uncul & 1 & HB1 \\
\hline Firmicutes; Bacillus & 1 & L5 \\
\hline Firmicutes; Staphylococcus & 2 & $\cdots$ \\
\hline Firmicutes; Aerococcus & 1 & $\cdots$ \\
\hline Nitrospirae; Nitrospirales; 0319-6A21; uncul & 2 & $\cdots$ \\
\hline Nitrospirae; Leptospirillum & 3 & HB2 \\
\hline Nitrospirae; Nitrospira & 8 & BR25, BR30, CC5-NMR, CC2-LC, LC5, L19A \\
\hline Planctomycetes; OM190; Other & 1 & $\cdots$ \\
\hline Planctomycetes; Phycisphaeraceae; CL500-3 & 1 & $\cdots$ \\
\hline Alphaproteobacteria; Rhodobacter & 1 & $\cdots$ \\
\hline Alphaproteobacteria; Tabrizicola & 2 & $\cdots$ \\
\hline Alphaproteobacteria; Reyranella & 1 & $\cdots$ \\
\hline Betaproteobacteria; Pelomonas & 1 & $\cdots$ \\
\hline Betaproteobacteria; Polaromonas & 2 & $\cdots$ \\
\hline Betaproteobacteria; Roseateles & 1 & $\cdots$ \\
\hline Betaproteobacteria; Comamonadaceae; Other & 1 & $\cdots$ \\
\hline Betaproteobacteria; Massilia & 1 & $\cdots$ \\
\hline Betaproteobacteria; Neisseriaceae; uncul & 1 & $\cdots$ \\
\hline Betaproteobacteria; Nitrosomonadaceae; uncul & 3 & $\cdots$ \\
\hline Deltaproteobacteria; Haliangium & 1 & $\cdots$ \\
\hline Gammaproteobacteria; Nitrosococcus & 1 & $\cdots$ \\
\hline Gammaproteobacteria; Escherichia-Shigella & 1 & $\cdots$ \\
\hline Gammaproteobacteria; Legionella & 1 & $\cdots$ \\
\hline Gammaproteobacteria; Pseudomonas & 1 & $\cdots$ \\
\hline Gammaproteobacteria; Polycyclovorans & 3 & BR17 \\
\hline Gammaproteobacteria; Xanthomonadales; uncul & 1 & CC1-NMR \\
\hline Gammaproteobacteria; Panacagrimonas & 1 & $\cdots$ \\
\hline Gammaproteobacteria; Stenotrophomonas & 1 & L1 \\
\hline Saccharibacteria; uncul & 1 & $\cdots$ \\
\hline TM6; uncul & 1 & $\cdots$ \\
\hline Verrucomicrobia; Opitutus & 1 & $\cdots$ \\
\hline Present at $\geq 5 \%$ in one pool & 28 & \\
\hline Present at $\geq 5 \%$ in two pools & 6 & \\
\hline Present at $\geq 5 \%$ in three or more & 6 & \\
\hline Total Genera $\geq 5 \%$ & 40 & \\
\hline
\end{tabular}




\section{Genera List: Hell Below Cave}

- Actinobacteria; Gaiellales; uncul

- Bacteroidetes; Sporocytophaga

- Candidatus Omnitrophica; uncul

+Chloroflexi; SAR202 clade; uncul

- Fibrobacteres; Fibrobacteraceae; possible genus 04

+Fibrobacteres; Fibrobacteraceae; uncul

Nitrospirae; Leptospirillum

+Nitrospirae; Nitrospira

+Nitrospirae; Nitrospirales; 0319-6A21; uncul

- Alphaproteobacteria; Rhodospirillaceae; uncul

+Betaproteobacteria; Nitrosomonadaceae; uncul

- Gammaproteobacteria; Coxiella

+Gammaproteobacteria; Polycyclovorans

+Deltaproteobacteria; Candidatus Entotheonella

- Deltaproteobacteria; Myxococcales; BIrii41; uncul

- Saccharibacteria; uncul

Other minor genera

Unassigned

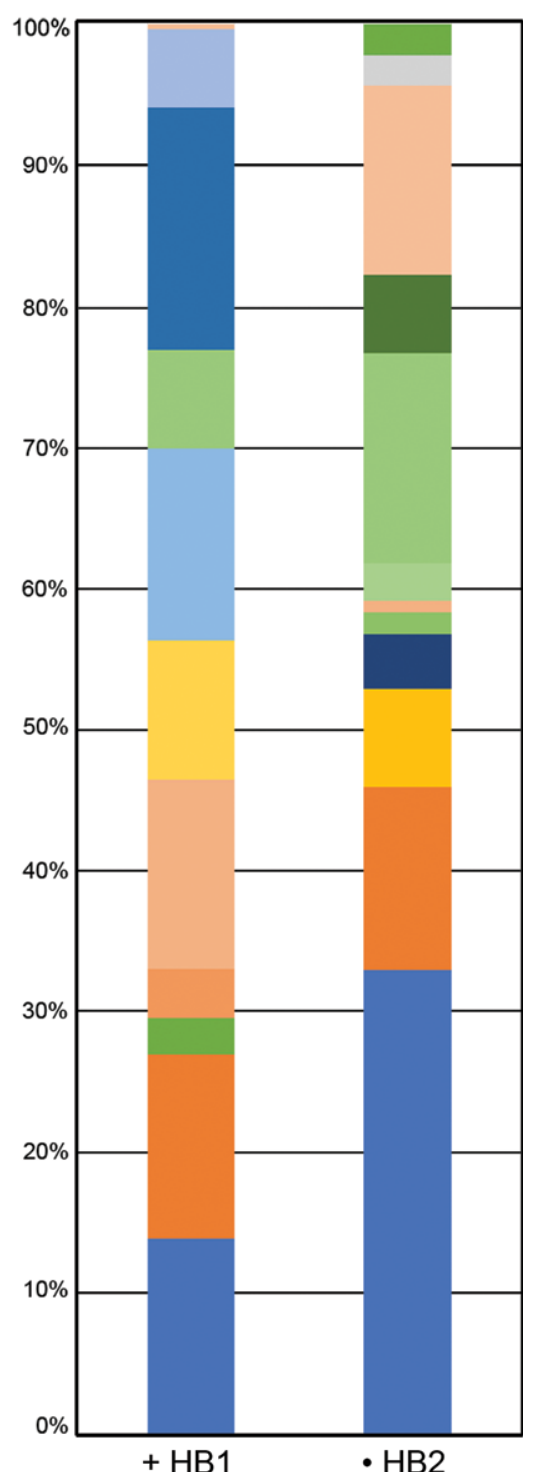

Figure 8. Comparison of genera at $>2 \%$ abundance in two relatively high diversity pools, HB1 (Simpson 0.916 ) and HB2 (Simpson 0.963). Pool HB2 drains into HB1 when full. Code: + genera present only in HB1; - genera present only in HB2. adjacent pools with higher diversity, Hell Below Cave pools HB1 and HB2 (Fig. 8, Table 1), out of 16 genera only one, Leptospirillum, was found in both pools. Of the other 15 genera, seven were in HB1 and eight were in HB2. Based on the setting, HB2 likely drains into HB1 during high flow conditions. Comparing again two adjacent Carlsbad Cavern pools CC1-NMR and CC5-NMR, including the highest diversity pool, CC1-NMR (Fig. 9, Table 1), out of 31 genera only two, Nitrospira and Polycyclorvorans were present in both pools. Of the other 29 genera, 19 were in CC1-NMR and 10 were in CC5-NMR. As for the Hell Below pair, pool CC5-NMR drains into pool CC1-NMR when full (Fig. 4C), although there are no historical reports of this happening. CC1-NMR also has $33 \%$ other minor genera, so even this plot does not fully show the diversity.

\section{DISCUSSION}

\section{Introduction}

Cave pools in an active epiphreatic zone are replenished with water and groundwater microbial assemblages on an annual basis (Shabarova et al., 2013; 2014), while pools in the vadose zone are thought to function more as "static collectors of microbial diversity" (Shabarova and Pernthaler, 2010). An alternative hypothesis, particularly for isolated vadose pools as the study pools, is that vadose pools act as incubators of diversity. Thus, the microbial community of each pool 
Genera List: Carlsbad Cavern; New Mexico Room

- Acidobacteria; Subgroup 6; uncul Acid

+Actinobacteria; Agrococcus

+Actinobacteria; Gaiella

+Actinobacteria; Janibacter

+Actinobacteria; Knoellia

+Actinobacteria; Lechevalieria

+Actinobacteria; Propionibacterium

- Bacteroidetes; Cytophagaceae; uncul

+Fibrobacteres; Fibrobacteraceae; possible genus 04

+Firmicutes; Bacillus

+Firmicutes; Paenibacillus

+Nitrospirae; Leptospirillum

Nitrospirae; Nitrospira

+Planctomycetes; Phycisphaeraceae; SM1A02

- Planctomycetes; Planctomyces

- Alphaproteobacteria; Novosphingobium

- Alphaproteobacteria; Reyranella

- Alphaproteobacteria; Rhodobacter

+Alphaproteobacteria; Rhodospirillales; KCM-B-15

- Betaproteobacteria; Burkholderiales; Other

+Betaproteobacteria; Comamonadaceae; uncul

- Betaproteobacteria; Comamonadaceae; Other

- Betaproteobacteria; Polaromonas

- Betaproteobacteria; Undibacterium

+Betaproteobacteria; Other

+ Gammaproteobacteria; Acinetobacter

+Gammaproteobacteria; Panacagrimonas

Gammaproteobacteria; Polycyclovorans

+Gammaproteobacteria; Xanthomonadales uncul

+Gammaproteobacteria; Xanthomonadales uncul, other

+ Proteobacteria; Other

Other minor genera

Unassigned

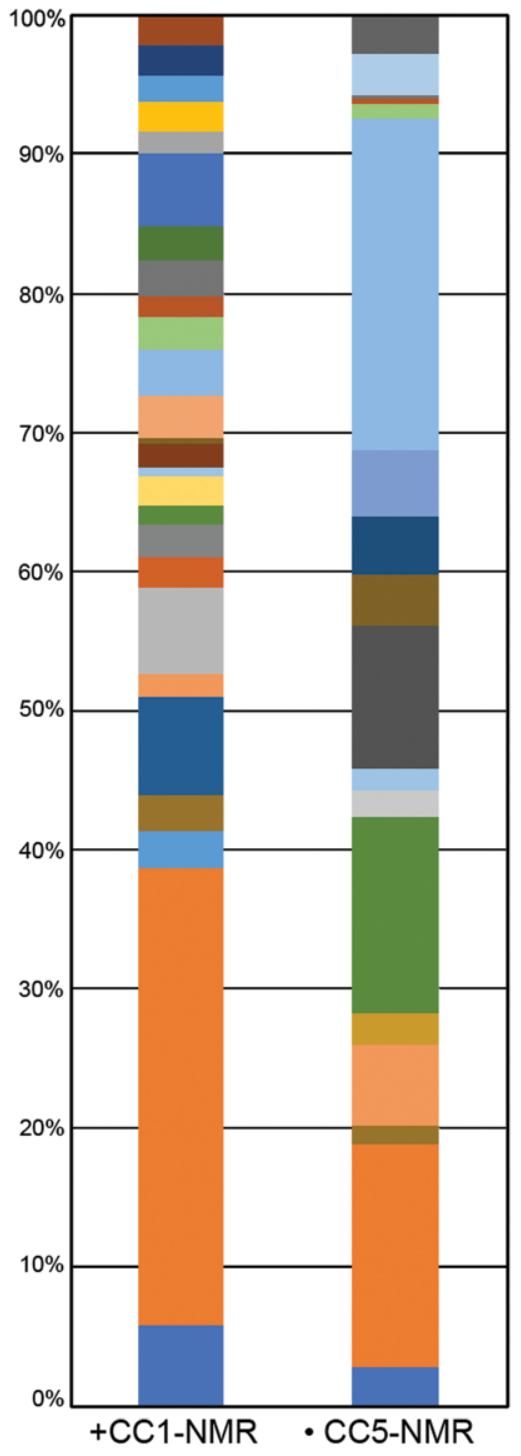

Figure 9. Comparison of genera $>2 \%$ abundance in two relatively high diversity pools, CC1-NMR (Simpson 0.981) and CC1-NMR (Simpson 0.907). CC5-NMR drains into CC1-NMR when full. Code: + genera present only in CC1-NMR; • genera present only in CC1-NMR. should reflect not only what can survive in the pool, but also how that community has evolved over time.

Based on estimates of the last time pools in Carlsbad were full (13.5 ka; Polyak et al., 2012), most of these individual pool ecosystems have likely been isolated for thousands of years, perhaps even longer. However, the Hell Below pools and Carlsbad Cavern New Mexico Room pools (HB1 - HB2, CC1NMR - CC2-NMR; Figs. 8 and 9), have probably been isolated from each other for a much shorter time period, perhaps decades since a large rain event overfilled the upper pools and drained into the lower pools. Since these pools share water, large differences in water chemistry are unlikely. Even so, the bacterial community differences between these paired pools are as great as between any two pools in this study (Figs. 8 and 9), so mere decades appear to be long enough for unique communities to evolve, even without significantly different chemistry. With this idea in mind, a number of topics can be addressed with this data set, including potential roles for the bacterial genera found, a comparison between examples of previously-studied cave microbial diversity and these pool results, and evaluating the possible human impact, particularly in the heavily-visited Big Room.

\section{Potential Roles of Bacteria in Study Pools}

The diversity of bacterial genera present in the study pools provides the opportunity to identify possible roles that these bacteria may play in cave pools. A predominant potential ecosystem function in the study pools is the presence of putative nitrogen cyclers. Nitrogen is often limited in caves due to their oligotrophic nature, especially in arid land caves (Levy, 2007; Ortiz et al., 2014). Research in caves over the last two decades (e.g., Holmes et al., 2001; Chen et al., 2009; Tetu et al., 2013; De Mandel et al., 2017) revealed possible key roles that microorganisms play in the cycling of nitrogen, including nitrification (ammonia and nitrite oxidation), dissimilatory nitrate reduction, and denitrification. The presence of several potential nitrogen cycling bacteria in the study pools suggests that nitrogen cycling may also be an important microbial role in cave pool ecosystems. 
The most abundant genus across these pools (Fig. 6; Table 4) is the bacterial genus Nitrospira, a well-known nitrite oxidizer (Koch et al., 2015). Nitrospira is highest in Carlsbad Cavern's Big Room pool BR25 pool with $36 \%$, and there are four other pools in Carlsbad Cavern with high Nitrospira varying between $20 \%$ to $26 \%$. Only one other study pool exhibited a greater than $20 \%$ abundance (L19A in Lechuguilla Cave). Across all study pools, eight pools ranged from $10 \%$ to $36 \%$ and only two study pools had no Nitrospira. Earlier studies (Holmes et al., 2001; Tetu et al., 2013) of an unusual formation in the flooded cave passages of Weebubbie Cave located in the Nullarbor region of Australia, documented the presence of Nitrospira, plus some other potential nitrification and denitrification archaea and bacteria.

In addition to Nitrospira, Pseudomonas, which is the most abundant genus in CC7-LC, is known to play a role in nitrification (Daum et al., 1998). Other abundant genera in Lechuguilla Cave and Hell Below Cave also include genera known to play roles in the nitrogen cycle (Tables 3 and 4). These include Bacillus (highest in L5), which can be a denitrifier (Pichinoty et al., 1983), and Leptospirillum, (highest in HB2), which can fix nitrogen (Parro and Moreno-Paz, 2004; Tyson et al., 2005) and is an iron-oxidizing chemolithoautotroph (Tyson et al., 2005). A few of the other abundant genera also play roles in the nitrification phase of the nitrogen cycle. These include the Nitrosomonadaceae, a family that includes Nitrosomonas, which oxidizes ammonia (Zhou et al., 2007; Chen et al., 2009, Movile Cave). Additionally, about half of Reyanella species are able to reduce nitrate (Pagnier et al., 2011), and Polaromonas, present in five study pools at $>1 \%$, has been documented as a denitrifier (Wang, et al., 2014; Jang et al., 2019).

Two of the study genera are common human skin bacteria: Propionibacterium and Staphylococcus (found in three and two study pools respectively at $>5 \%$ ), but can also have roles in the nitrogen cycle. Besides being known as a common human skin bacterium (Stackebrandt et al., 2006), Propionibacterium is also known to reduce nitrate (Allison et al., 1989; Swart et al., 1998). While Staphylococcus is known to be a common member of the human skin microbiome (Grice and Segre, 2011), some species of Staphylococcus have recently been documented to have the ability to fix nitrogen (Yousuf et al., 2020).

An interesting uncultured organism found at 13\% abundance in both CC7-LC (Carlsbad Cavern) and in HB2 (Hell Below Cave), belongs to the Candidatus Omnitrophica, previously known as OP3. Sequences classified in this group were recovered from one of three cave pools studied by Shabarova and Pernthaler (2010). The pool in which Candidatus Omnitrophica was found by Shabarova and Pernthaler (2010) contained significantly higher $\mathrm{NO}_{3}{ }^{-}$levels and Nitrospira, a nitrite-oxidizing bacterium. A more recent paper by Momper et al. (2017), who studied the microbiome of deep terrestrial fluids, differentiates $O P 3$ from Candidatus Omnitrophica, describing them as two candidate phyla. However, the NCBI Taxonomy database (NCBI, 2020) only recognizes the Omnitrophica candidate phylum, and more recent papers utilize the Candidatus Omnitrophica nomenclature (Rivas-Marı and Devos, 2018; Kirs et al., 2020).

Bacillus, as previously noted, is extremely high in Lechuguilla pool L5 (69\%), but is not present in Lechuguilla Cave pool L1, $30 \mathrm{~m}$ from L5, which poses a mystery of why it's there and not also in pool L1. Bacillus is very common in soils and natural waters (Logan and De Vos, 2015). In caves, it is the most common cultured bacteria associated with calcite precipitation (Cacchio et al., 2003; Ferris et al., 2003; Dhami et al., 2018; Tredici et al., 2018). This versatile genus is often involved in the nitrogen cycle (Pichinoty et al. 1983) but can also oxidize Mn and Fe (De Vrind et al., 1986; Logan and De Vos, 2015). The oddity, therefore, is not in its presence but in its unusual abundance in Lechuguilla Cave pool L5. Although L5 is more yellow in color than most, which might suggest slightly higher iron, other pools in this study (that do not have the high Bacillus) are equally yellow. Lavoie and Northup (2005) found greater presence of high-temperature Bacillus (putatively from cavers' boots that hiked across hot desert soils) in areas of Lechuguilla Cave with high human impact, which could suggest that cavers brought Bacillus, or its spores, into the cave on their boots. However, because pool L5 is so far from the entrance, this seems less likely.

Polaromonas was first isolated from Antarctica (Irgens et al., 1996) and it remains best-known from glacial and periglacial settings (Vimercati et al., 2019). However, it has also been found in a number of cave settings (Northup et al., 2003; Shabarova and Pernthaler, 2010; Ortiz et al., 2013; Yun et al., 2016b). Polaromonas is present in five pools (>1\%) and abundant in two Carlsbad Cavern pools (BR44, $13 \%$, CC5-NMR $14 \%$ ), but it is not the dominant genus in any pool (Table 4). It is a metabolically diverse heterotroph, able to use a wide variety of energy sources (Vimercati et al., 2019) and survive in oligotrophic conditions (Loy et al., 2005; Ortiz et al., 2013). Its ability to denitrify nitrogen suggests it could play a role in the nitrogen cycle in Carlsbad Cavern, or its heterotrophic nature could suggest it is taking advantage of areas with enrichment from human visitation.

Haliangium is only found in higher abundance $(16 \%)$ in one study pool, Lechuguilla Cave pool L1. Although the only cultured members of this genus are obligate halophiles (Ivanova et al., 2010; Albataineh and Stevens, 2018; Mohr, 2018), Haliangium has been found in several low-salt cave samples, including moonmilk (Engel et al., 2013) and cave sediments (de Mandel et al., 2017; Yasir, 2018). Mohr (2018) suggested that the diversity of this hard-to-culture group is larger than currently known, so it may not be as halophilic in caves as currently seen in other habitats.

Acidobacteria Subgroup 6 are uncultured isolates that are present in seven pools, ranging from $1 \%$ to $4 \%$ in six of the pools, and with the highest occurrence being $18 \%$ in Lechuguilla Cave pool L19A (Table 3, Figs. 6, 7, 9). This Aci- 
dobacteria subgroup has been characterized from a variety of soils (Barns et al., 2007; Li et al., 2019), including forest and grassland soils, with it being dominant in the latter, which are less oligotrophic (Naether et al., 2012). This subgroup has also been documented as common in Altamira Cave in Spain and Roman Catacombs (Zimmermann et al., 2005, 2006) and Lower Kane Cave (Meisinger et al., 2007).

\section{Microbial Diversity of Caves vs. Study Cave Pools}

In this study, no two pools contain the exact same set of phyla/Proteobacterial classes and no phylum/Proteobacterial class is present in all pools. (Fig. 5). Additionally, there are large variations in three commonly used diversity indices (Chao1, Shannon, and Simpson; Table 1; Fig. 10). The Chao1 values are an estimate of richness in the sample, or how many OTUs may be present in each pool. Shannon and Simpson indices are both estimates of evenness, or whether each OTU is present in an equal quantity. The Shannon index is more influenced by rare OTUs, while the Simpson is a probability value that is influenced by dominant OTUs. We chose to use both, because of the variability in evenness of the pools.

A comparison of the diversity indices from the study pools with other vadose cave pool bacteria studies is hindered by the general lack of such studies. Shabarova et al. (2010) looked at a pair of vadose pools, but did not present diversity indices. Sauro et al. (2018) included one vadose pool in their study of an orthoquartzite cave and reported higher Shannon (7.854) and Simpson (0.9916) than the carbonate pools in this study. Interestingly, despite the higher Shannon index, they detected a lower number of bacterial phyla (11 total phyla present, but only 3 phyla $>2 \%$, Sauro et al., 2018, their Table S5; versus this study with an average of 14 phyla present, and an average of 5.3 phyla at $>2 \%$ ). In addition, they have fewer genera in their one pool ( 6 at $>2 \%$; Sauro et al., 2018, their Table S5) than most of our study pools (8 at $>2 \%$, range 5-16), even though they have a higher Simpson. The dominant groups include Alphaproteobacteria Rhizobiales unclassified (40 \%), and Acidobacteria (27 \%), mainly Acidobacteria Gp13 (18 \%; Sauro et al., 2018, Table $\mathrm{S5})$, neither of which are present in our study pools. However, this is not surprising as a silica system is very different from a carbonate system.

Results from other carbonate cave habitats are available (Ortiz et al., 2013: Alonso et al., 2019; Thompson et al., 2019). However, there are several challenges in such a comparison. These studies sampled surfaces of speleothems or cave sediment, whereas the study pool samples are planktonic. Surfaces are known to have more microbes than planktonic communities (Savio et al., 2018). In addition, some studies group samples together from similar settings, but different caves (Lavoie et al., 2017; Alonso et al., 2019; Thompson et al., 2019), whereas this study has not grouped the data, preferring to look at each pool separately. Different sequencing methods between studies also limit some comparisons.

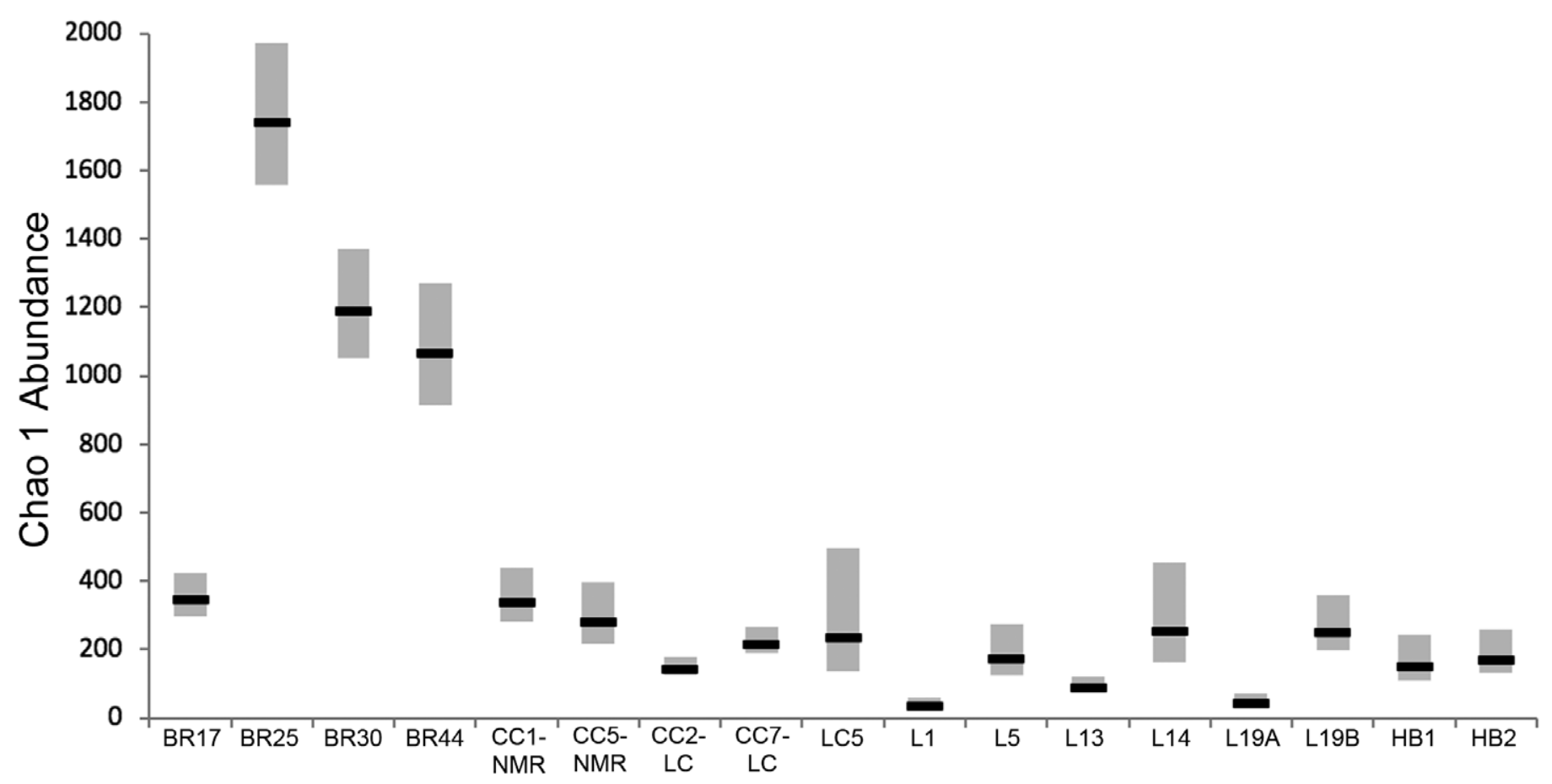

Figure 10. Chao 1 values for the sampled pools. The black line is the Chao value. The gray bars represent the upper and lower bounds of the diversity calculation. 
Ortiz et al. (2013) compared speleothem surfaces with surface soil in Kartchner Caverns, an arid land cave in Arizona. The speleothems had much higher Chao1 values (2067-3693) than the study pools, but comparable Shannon (4.3-6.1; Ortiz et al., 2013, their Table 1). Interestingly, they found three separate communities based on variations in Actinobacteria, Proteobacteria, and Acidobacteria and interpreted this as variation in the chemical profile of the speleothems. In comparison to these studies, the study pools have much less Actinobacteria and Acidobacteria, and much more Nitrospirae (Fig. 5, Table 2),

Sampling different microbial mats in lava caves, Lavoie et al. (2017) report much lower diversity in both Shannon ( 1.4 to 2.6, with some outliers) and Simpson ( 0.40 to 0.75; Lavoie et al., 2017; their Fig. 3 and Supplemental S2) for grouped data. Their top cave groups were Actinobacteria (37\% to $44 \%$ ), Gammaproteobacteria (19\% to $24 \%$ ), Alphaproteobacteria (10\%), and Nitrospirae (4\% to $11 \%)$. Although these groups are also found in these cave pool samples, notable differences include Actinobacteria and Nitrospirae: Actinobacteria are much less common ( $>5 \%$ in six pools, maximum $21 \%$ in Carlsbad Cavern pool CC1- NMR) and Nitrospirae is much more common (>20 \% in seven pools; Fig. 5, Table 2).

Alonso et al. (2019) used cave wall samples from nine karst caves in the Dordogne region of France to compare more or less anthropized caves. Looking just at the bacterial results, their Chao1 results are higher (using a different method), their Shannon values are similar ( 4.1-5.2), and their Simpson values are higher (above 0.95 except for one cave with values of $\sim 0.82-0.95$; Alonso et al., 2019, Fig. 2). The Proteobacteria ( $14 \%$ to $56 \%$, undifferentiated) and Actinobacteria (11\% to $49 \%$ ) were their most abundant phyla, as is common on carbonate cave surfaces (TomczykŻak and Zielenkiewicz, 2016).

Thompson et al. (2019) found that speleothems had lower Chao1, Shannon, and Simpson diversity than did the cave sediment and surface soils. All of their Chao1 values were much higher than the study pools. Their much higher Chao1 values may be a reflection of their different methods. Looking at Shannon and Simpson, speleothems are closest to the cave pools (Shannon $\sim 4.7$, Simpson $\sim 0.989$, Thompson et al., 2019, Fig. 1; compare to Table 1), while both cave sediment and surface soils are more diverse. The most abundant cave phyla are similar to the other studies with the top three being Actinobacteria (speleothems $19.47 \%$, cave sediment $21.91 \%$ ), Proteobacteria (speleothems $14.21 \%$, cave sediment $16.05 \%$ ), and Acidobacteria (speleothems $9.85 \%$, cave sediment $2.15 \%$, Thompson et al., 2019, Table 1). Nitrospriae were $<1 \%$ of any sample.

Thus, the diversity values of cave samples are variable, and the study cave pool samples fall within that variability. The dominant phyla, however, are notably different. Although Proteobacteria are abundant in most cave samples, Actinobacteria and Acidobacteria are more common in surface samples and Nitrospirae are more common in the cave pool samples. Actinobacteria are very common in caves but are known mainly from surfaces (Tomczyk-Żak and Zielenkiewicz, 2016), which likely explains their greater abundance in other studies than the cave pools. Nitrospirae are known to inhabit aquatic environments (Tomczyk-Żak and Zielenkiewicz, 2016), which may help explain the higher pool abundances.

The means of diversity indices, however, do not tell the whole story. Although the cave pool average values are similar to other cave samples, the range of values is much higher. Looking at the carbonate cave samples, the Kartchner speleothems have a Shannon range of values of $\sim 1.7$ (4.37 to 6.06; Ortiz et al., 2013, Table 1), the Appalachian cave speleothems range $\sim 2.4$ ( $\sim 3.5$ to $\sim 5.9$; Thompson et al., 2019 , Fig. 1); and the French caves of $\sim 2.2(\sim 3$ to $\sim 5.2$, Alonso et al., 2019, Fig. 2). The study cave pools, in contrast, have a range in Shannon values of 3.9 (2.5 to 6.4, Table 1). The range in Simpson values is also higher for our cave pools (Table 1), suggesting there is a greater variation among pools than is represented just by looking at the diversity indices.

A few of the cave pools are strongly dominated by single OTUs. When looking at the distribution of the phyla/proteobacterial classes of the two pools with the lowest Simpson values, Carlsbad Cavern pool BR17 and Lechuguilla Cave pool L5, (Fig. 5), it is apparent there is not an even distribution, as both pools are dominated by a single phylum/proteobacterial class. Looking closer at these two pools, BR17's low Simpson index value is likely due to the dominance of the Gammaproteobacteria, Polycyclovorans (56 \%), and L5 is dominated by Fimicutes, Bacillus (69 \%; Fig. 6 and Table 3). Additional pools with relatively low Simpson values include Lechuguilla Cave pools L1 (0.809) and L19B (0.842), both also dominated by single genera, but not as strongly. Other pools have Shannon and Simpson values comparable to the speleothem data of Thompson et al. (2019). For example, Carlsbad Cavern pools CC1-NMR and CC7-LC (Shannon 6.4 and 6.0; Simpson 0.981 and 0.976, respectively) have higher Shannon values, but slightly lower Simpson values than the Appalachian speleothems. Thus, the differences of the alpha diversity index values in the seventeen pools across three cave systems indicates that sample evenness is variable, even within the same cave system.

\section{Paired comparisons of distant vs. adjacent pools}

To examine this variability, the genera from three paired pools were compared (Figs. 7, 8, and 9). Pools Carlsbad Cavern BR17 and Lechuguilla Cave L19A both have lower diversity and may be impacted by human activity. As dis- 
cussed previously, BR17 is adjacent to the primary trail in the Big Room of Carlsbad Cavern. L19A was a common water and rest stop for expeditions through Lechuguilla Cave. BR17 has a moderate Chao1 value (343), but a low Simpson index value (0.677) (Table 1). L19A has a low Chao1 value (40), but a moderate Simpson index value (0.881). The two pools have the same Shannon index value (3.5). Despite the similar Shannon, only two genera are shared between the two pools at $>2 \%$, Nitrospira and an uncultured Acidobacteria (Fig. 7). The abundance of the two genera is different, with both more common in L19A. Of the remaining genera found in greater than $2 \%$ abundance, none are shared between the two cave pools. L19A has Pseudomonas and Escherichia-Shigella present in the pool; both are known human contaminates. BR17 has $56 \%$ Polycyclovorans, a hydrocarbon degrader (Gutierrez et al., 2013), which may be related to asphalt from the nearby trail. Although both pools have been impacted by human visitation, they have been impacted in different ways, which can be seen in both the alpha diversity index values and the presence of various OTUs.

The two pools in Hell Below Cave are adjacent to each other, and HB1 has likely drained into HB2 during major rainfall events within the last few decades. However, results from Shabarova et al. $(2013,2014)$, indicate that the distribution of bacteria within a cave pool can change within a few months after a perturbation. In Hell Below Cave, the two pools have similar Chao1, Simpson, and Shannon values, but have very few shared OTUs. These two pools are adjacent to each other and likely share water, suggesting they receive similar inputs from the vadose zone and experience similar climates. The distribution of phyla in each pool (Table 1) is not dominated by a single phylum. Nitrospirae is the highest at $30 \%$ in HB1. There are 16 genera found at greater than $2 \%$ in these pools (Fig. 8). Of these 16 genera, only three are shared between the two pools, the rest are only found in one of the pools.

In the New Mexico Room of Carlsbad Cavern, pool CC5-NMR flows into CC1-NMR when it overflows, and it was nearly full at the time of sample collection (Fig. 4C). These two pools have likely shared water during a major rainfall event within the last several decades, similar to the two pools in Hell Below Cave. However, unlike the Hell Below Cave pools, the pools in the New Mexico Room have different alpha diversity index values and genera present (Table 1, Fig. 9). CC1-NMR has the highest Shannon and Simpson index values of the seventeen pools in this study, 6.4 and 0.981 respectively (Table 1). CC5-NMR has moderate Shannon and Simpson index values of 4.7 and 0.907 . There are 30 genera found between the two pools, but only six are found in both pools.

Thus, although the diversity index values of individual pools are similar to that of other cave systems (see above), each pool has its own community, indicated by the low overlap between pool genera (Figs. 6-9, Tables 3 and 4). Studies on pool water chemistry in both Carlsbad Cavern and Lechuguilla Cave have shown the pools are broadly similar, albeit with considerable minor chemical variation among pools (Chapman et al., 1992; Turin and Plummer, 2000; Levy, 2007a; Forbes, 2000). These chemical differences are likely minimal between the adjacent pools that share water in Carlsbad Cavern's New Mexico Room and Hell Below Cave, yet these pools share only a few genera (Figs. 8 and 9 ). Rather than a single stable cave pool community, adapted to the cave pool system, the study data show 17 different communities despite relatively similar conditions. These data support the hypothesis that each pool is a unique, isolated ecosystem, with differences likely caused as much by the isolation of each pool as by variable water chemistry. Within some of the study cave pools, however, this isolation has been affected by human impact, which can have an impact on microbial communities (see discussion below).

\section{Effects of human visitation on pool communities}

The study pools vary in terms of alpha diversity and show significant differences in microbial community structure. They also vary in terms of human visitation with the Big Room (Carlsbad Cavern) having by far the most visitors per year (300,000/year to 500,000/year), and Lechuguilla Cave and Hell Below Cave having the least (<100/year to 200/ year). In a previous study of the impact of human visitation in Carlsbad Cavern, Griffin et al. (2014) reported significant human impacts of visitors on the microbiota. Collecting samples from the cave air, they reported that Staphylococcus spp., noted above as a common human skin inhabitant (Stackebrandt et al., 2006), were the dominant bacteria cultured along tourist trails. Knoellia sp. was most common off trail. Knoellia is a novel genus of Actinobacteria, first isolated from a cave in China (Groth et al., 2002), which was also found in this study in one of the Carlsbad Cavern New Mexico Room pools (CC1-NMR, Fig. 9). Griffin et al. (2014) also utilized genetic sequencing to show that Enterobacteriaceae dominated along the descent trail railing and in the Lunchroom, which is not unexpected given the number of fecal deposits from visitors that rangers clean up. They concluded that humans were important sources of non-indigenous microorganisms in Carlsbad Cavern.

The four pools in the Big Room of Carlsbad Cavern have the highest number of OTUs and the highest Chao values of any pools. The larger numbers of OTUs in the Big Room could be driven by a variety of factors, such as increased energy sources from the illumination, shed skin cells, or construction materials. This last item is supported by the presence of the genus Polycyclovorans, particularly in Big Room pools, which can facultatively use hydrocarbons for energy (Gutierrez et al., 2013; Thompson et al., 2018). The trail system in the Big Room is asphalt (Brooke, 1996, Van 
der Heijde et al., 1997) and BR17, which has $56 \%$ Polycyclovorans, is directly below the trail and contains debris from the trail (Fig. 4A). However, Polycyclovorans has been documented as a marine genus (Berry and Gutierrez, 2017); other genera isolated from marine environments are found in pools in each cave system. Polycyclovorans has also been documented in soils (Lu, 2018), and will probably be discovered in other environments as the knowledge of microbial communities expands. In addition, the Polycyclovorans genus is also found in Carlsbad Cavern's New Mexico Room pools and one pool from Hell Below Cave (Table 3), which do not have asphalt trails.

In a study by Lavoie et al. (2017) in Lava Beds National Monument (LABE) volcanic caves, there was only one Staphylococcaeae identified, and only 25 OTUs of Enterbacteriacae identified to the level of family detected at any LABE cave or surface sample. Lavoie et al. (2017) hypothesized that there is a threshold of visitors before the effects of human visitation are observed, which is greater than the 30,000/y seen in LABE. The Carlsbad Cavern Big Room pools greatly exceed this threshold with 300,000 visitors/year to 500,000 visitors/year over the last decades. However, the presence of human-associated genera such as Staphylococcus and Pseudomonas (Table 4) does not correlate with visitation numbers. Staphylococcus is most common in Lechuguilla Cave and absent in the Big Room. Pseudomonas is present in some, but not all Big Room pools, but also in four Lechuguilla Cave pools. These genera are also known to play roles in the nitrogen cycle, so perhaps they are not simply indicators of human impact in these pools.

Another recent study by Alonso et al. (2019) examined the differences in microbial and micro-eukaryotic diversity in four pristine and four anthropized caves, plus two sections of the highly visited Lascaux Cave (France). Of particular interest was differences noted in the bacterial phylum Bacteroidetes, which were higher in anthropized caves, and $\mathrm{Ni}$ trospirae, which were lower in anthropized caves versus pristine caves. In this study, Bacteroidetes were present in all Carlsbad Cavern pools, varying from $1 \%$ to $26 \%$, but in only two of the Lechuguilla Cave (L1 and L5, $1 \%$ to $2 \%$ ), and one of the Hell Below Cave pools (HB2, $3 \%$ ) (Table 2).

This study observed considerable variation in Nitrospirae across the study pools (Fig. 5). Nitrospirae were present in all Carlsbad Cavern pools, varying from $2 \%$ to $36 \%$, with five of the pools having $>20 \%$ occurrence, and the highest percentage of $36 \%$ being found in the Big Room. In Lechuguilla Cave pools, Nitrospirae varied from $1 \%$ to $21 \%$, with only two pools at $10 \%$ and $21 \%$ across pools with varying visitation (but still low in comparison to Carlsbad Cavern). Hell Below Cave had $15 \%$ and $30 \%$ in its pools, with low visitation. Thus, both high and low impact settings can have high Nitrospirae, in contrast with Alonso et al. (2019) who found that Nitrospirae were more abundant on the walls in less anthropized caves (5\% to $10 \%$ ). The different pattern of Nitrospirae occurrence in the cave pools suggests further investigation into how the unique bacterial communities utilize the nitrogen cycle and what drives the community make-up of each pool.

\section{Broader Implications}

Studies of microbial diversity in caves are often trying to characterize either different caves or different sample types in the context of larger questions like human impact (Adetutu et al., 2012; Leuko et al., 2017; Alonso et al., 2019), soil contributions to cave ecosystems (Ortiz et al., 2013; Lavoie et al., 2017; Thompson et al., 2019), or variation between microbial mat types (Lavoie et al., 2017). It is common to group samples from different locations (Lavoie et al., 2017; Alonso et al., 2019; Thompson et al., 2019). Ortiz et al. (2013) instead looked at individual speleothems and found different microbial communities for adjacent stalactites. They attributed the differences to varying water and speleothem chemistry. This study of vadose pools also found unique ecosystems, even for adjacent pools that likely share water occasionally. Thus, we suggest an additional variable in the cave ecosystem may be time; communities that are isolated from each other will evolve independently over time. This contrasts with groundwater ecosystems that vary less over larger distances (Wegner et al., 2019), perhaps because of more interaction in the connected aquifer. Thus, the common habit of grouping samples, while useful for some questions, misses some of the differences in diversity present in cave ecosystems. Rather, caves may harbor a wide variety of isolated ecosystems, each one potentially containing a unique community impacted by both the local conditions and the amount of time it has been isolated. Further exploration of this hypothesis in different kinds of cave ecosystems would be useful.

\section{Future Directions}

Future studies will focus on elucidating the geochemistry of the pools, expanding the sequencing to include the Archaea and expand the Bacteria, and conducting metagenomic and transcriptomic analyses of pool water. The extensiveness of potential nitrogen cycling bacteria in the study samples points to the need to expand future studies to sequencing of the Archaea present, using Archaea-specific primers for more comprehensive recovery (Bahram et al. 2019). Metagenomic sequencing will confirm what nitrogen cycle genes, if any, are present in the pool inhabitants and transcriptomics, if successful, will confirm what nitrogen cycling is taking place. Simultaneous sampling for water chemistry is required to better test the controls on diversity. Expanding the analysis of pool water microbial analyses to other cave types and climate settings would be very beneficial as the number of cave water pool studies is very low. Also, long-term studies are needed to determine the stability of the communities. We also suggest that additional test- 
ing of the impact of human activities and built environments that are installed to facilitate tourists in caves with different visitation levels is essential to understanding how to mitigate such impacts. Such studies would expand the knowledge of microbial diversity in caves substantially.

\section{CONCLUSIONS}

The 17 study pools across three caves represent unique bacterial communities, suggesting they are isolated systems. Nitrospirae, Alphaproteobacteria, Betaproteobacteria and Gammaproteobacteria were the most abundant phyla/ proteobacterial classes in over half the cave pools. The most widespread genus observed was Nitrospira, while nine other top genera included Polyclorovans, Polyclorovans, Propionibacterium, Polaromonas, Haliangium, Bacillus, Subgroup 6 uncultured Acidobacteria, Candidatus Omnitrophica, and uncultured Nitrosomonadaceae. Prior studies of several of these genera suggest roles in the nitrogen cycle for pool bacteria. These data suggest there is some evidence of human contamination, but do not clearly support it as a major factor in the diversity observed. Although Proteobacteria are abundant in both settings, the dominant bacterial phyla on speleothems and other surfaces (Actinobacteria and Acidobacteria), are different than that found in the study cave pools (Nitrospirae). Rather than a single stable cave pool community, adapted to the cave pool system, these data show 17 different communities despite relatively similar conditions. These data support the hypothesis that each pool is a unique, isolated ecosystem, with differences likely arising from the isolation of each pool and not just from different water chemistry. These data also suggest that to accurately assess diversity present in cave ecosystems future cave studies should not group samples.

\section{ACKNOWLEDGEMENTS}

We are very grateful to our funding agencies, the National Science Foundation Geobiology and Low-Temperature for the collaborative grant EAR-0719507 to Melim, Northup, and colleagues, and to T\&E, Inc. for funding for the sequencing. We thank Carlsbad Caverns National Park for our sampling permit CAVE-2008-SCI-0004 and the U.S. Forest service for sampling permit FS-2700-4 (10/09). Stan Allison, Dale Pate, and Paul Burger of the Carlsbad Caverns National Park Cave Resources Office were very supportive of our fieldwork. Pat Cicero, lan McMillan, Thibault Datry, and Aaron Stockton did a great job of water sampling in Lechuguilla Cave. All cave photographs are courtesy of Dr. Kenneth Ingham or Pat Cicero.

\section{REFERENCES}

Adetutu, E., Thorpe, K., Shahsavari, E., Bourne, S., Cao, X., Fard, R., Kirby, G., and Ball, A., 2012, Bacterial community survey of sediments at Naracoorte Caves, Australia: International Journal of Speleology, v. 41, no. 2, p. 137-147. https://doi.org/10.5038/1827-806X.41.2.2.

Albataineh, H., and Stevens, D.C., 2018, Marine myxobacteria: A few good halophiles: Marine Drugs, v. 16, no. 6., p. 209. https://doi.org/10.3390/ md16060209.

Allison, C., and Macfarlane, G.T., 1989, Dissimilatory nitrate reduction by Propionibacterium acnes: Applied and Environmental Microbiology, v. 55, p. 2899-2903. https://doi.org/10.1128/AEM.55.11.2899-2903.1989.

Alonso, L., Pommier, T., Kaufmann, B., Dubost, A., Chapulliot, D., Dore, J., Douady, C.J., and Moenne-Loccoz, Y., 2019, Anthropization level of Lascaux Cave microbiome shown by regional-scale comparisons of pristine and anthropized caves: Molecular Ecology, v. 28, no. 14, p. 3383-3394. https://doi.org/10.1111/mec.15144.

Bahram, M., Anslan, S., Hildebrand, F., Bork, P., and Tedersoo, L., 2019, Newly designed 16S rRNA metabarcoding primers amplify diverse and novel archaeal taxa from the environment: Environmental Microbiology Reports, v. 11, no. 4, p. 487-494. https://doi.org/10.1111/17582229.12684.

Barns, S.M., Cain, E.C., Sommerville, L., and Kuske, C.R., 2007, Acidobacteria phylum sequences in uranium-contaminated subsurface sediments greatly expand the known diversity within the phylum: Applied and Environmental Microbiology, v. 73, no. 9, p. 3113-3116. https://doi. org/10.1128/AEM.02012-06.

Barton, H.A., and Northup, D.E., 2007, Geomicrobiology in cave environments: Past, current and future perspectives: Journal of Cave and Karst Studies, v. 69 , no. 1, p. 163-178.

Barton, H.A., Taylor, N.M., Kreate, M.P., Springer, A.C., Oehrle, S.A., and Bertog, J.L., 2007, The impact of host rock geochemistry on bacterial community structure in oligotrophic cave environments: International Journal of Speleology, v. 36, p. 93-104. https://doi.org/10.5038/1827806X.36.2.5.

Berry, D., and Gutierrez, T., 2017, Evaluating the detection of hydrocarbon-degrading bacteria in 16S rRNA gene sequencing surveys: Frontiers in Microbiology, v. 8, p. 896. https://doi.org/10.3389/fmicb.2017.00896.

Blyth, A.J., Hartland, A., and Baker, A., 2016, Organic proxies in speleothems - New developments, advantages and limitations: Quaternary Science Reviews, v. 149, p. 1-17. https://doi.org/10.1016/j.quascirev.2016.07.001.

Brannen-Donnelly, K., and Engel, A.S., 2015, Bacterial diversity differences along an epigenic cave stream reveal evidence of community dynamics, succession, and stability: Frontiers in Microbiology, v. 6, p. 729. https://doi.org/10.3389/fmicb.2015.00729

Brewer, T.E., and Fierer, N., 2018, Tales from the tomb: the microbial ecology of exposed rock surfaces: Environmental Microbiology, v. 20, no. 3, p. 958-970. https://doi.org/10.1111/1462-2920.14024.

Brooke, M., 1996, Infiltration Pathways at Carlsbad Caverns National Park Determined by Hydrogeologic and Hydrochemical Characterization and Analysis: Colorado School of Mines, $182 \mathrm{p}$.

Budd, D.A., Frost, E.L., Huntington, K.W., and Allwardt, P.F., 2013, Syndepositional deformation features in high-relief carbonate platforms: Long-lived conduits for diagenetic fluids: Journal of Sedimentary Research, v. 83, no. 1, p. 12-36. https://doi.org/10.2110/jsr.2013.3.

Cacchio, P., Ercole, C., Cappuccio, G., and Lepidi, A., 2003, Calcium carbonate precipitation by bacterial strains isolated from a limestone cave and from a loamy soil: Geomicrobiology Journal, v. 20, p. 85--98. https://doi.org/10.1080/01490450303883. 
Caporaso, J.G., Kuczynski, J., Stombaugh, J., Bittinger, K., Bushman, F.D., Costello, E.K., et al., 2010, QIIME allows analysis of high-throughput community sequencing data: Nature Methods, v. 7, no. 5, p. 335-336. https://doi.org/10.1038/nmeth.f.303.

Carmichael, S., and Bräuer, S.L., 2015, Microbial diversity and manganese cycling: a review of Mn-oxidizing microbial cave communities, in Engel, A.S., ed., Microbial Life of Cave Systems: Boston, MA, USA, De Gruyter, p. 137-160.

Carmichael, M.J., Carmichael, S.K., Santelli, C.M., Strom, A., and Bräuer, S.L., 2013a, Mn(II)-oxidizing Bacteria are abundant and environmentally relevant members of ferromanganese deposits in caves of the Upper Tennessee River Basin: Geomicrobiology Journal, v. 30, no. 9, p. 779-800. https://doi.org/10.1080/01490451.2013.769651.

Carmichael, S., Carmichael, M., Strom, A., Johnson, K., Roble, L., Gao, Y., and Brauer, S., 2013b, Sustained anthropogenic impact in Carter Saltpeter Cave, Carter County, Tennessee and the potential effects on manganese cycling: Journal of Cave and Karst Studies, v. 75, no. 3, p. 189-204. https://doi.org/10.4311/2012MB0267.

Chapman, J.B., Ingraham, N.L., and Hess, J.W., 1992, Isotopic investigation of infiltration and unsaturated zone flow processes at Carlsbad Cavern, New Mexico: Journal of Hydrology, v. 133, p. 342-363. https://doi.org/10.1016/0022-1694(92)90262-T.

Chelius, M.K., and Moore, J.C., 2004, Molecular phylogenetic analysis of Archaea and Bacteria in Wind Cave, South Dakota: Geomicrobiology Journal, v. 21, p. 123-134. https://doi.org/10.1080/01490450490266389.

Chen, Y., Wu, L., Boden, R., Hillebrand, A., Kumaresan, D., Moussard, H., Baciu, M., Lu, Y., and Colin Murrell, J., 2009, Life without light: microbial diversity and evidence of sulfur- and ammonium-based chemolithotrophy in Movile Cave: International Society for Microbial Ecology Journal, v. 3, no. 9, p. 1093-1094. https://doi.org/10.1038/ismej.2009.57.

Daum, M., Zimmer, W., Papen, H., Kloos, K., Nawrath, K., and Bothe, H., 1998, Physiological and molecular biological characterization of ammonia oxidation of the heterotrophic nitrifier Pseudomonas putida: Current Microbiology, v. 37, p. 281-288. https://doi.org/10.1007/ s002849900379,

De Mandal, S., Chatterjee, R., and Kumar, N.S., 2017, Dominant bacterial phyla in caves and their predicted functional roles in C and N cycle: BMC Microbiology, v. 17, no. 1, p. 90. https://doi.org/10.1186/s12866-017-1002-x.

De Vrind, J.P.M., De Vrind-De Jong, E.W., De Voogt, J.-W.H., Westbroek, P., Boogerd, F.C., and Rosson, R.A., 1986, Manganese oxidation by spores and spore coats of a marine Bacillus species: Applied and Environmental Microbiology, v. 52, p. 1096-1100. https://doi.org/10.1128/ AEM.52.5.1096-1100.1986.

Dhami, N.K., Mukherjee, A., and Watkin, E.L.J., 2018, Microbial Diversity and Mineralogical-Mechanical Properties of Calcitic Cave Speleothems in Natural and in Vitro Biomineralization Conditions: Frontiers in Microbiology, v. 9, p. 40. https://doi.org/10.3389/fmicb.2018.00040.

Dunham, R.J., 1972, Capitan Reef, New Mexico and Texas: Facts and Questions to Aid Interpretation and Group Discussion, Permian Basin Section-SEPM Publication 72-14: Midland, TX, Permian Basin Section-SEPM Publication 72-14, 291 p.

Edgar, R.C., 2010, Search and clustering orders of magnitude faster than BLAST: Bioinformatics, v. 26, no. 19, p. 2460-2461. https://doi. org/10.1093/bioinformatics/btq461.

Engel, A.S., 2010, Microbial diversity of cave ecosystems, in Barton, L.L., Mandl, M., and Loy, A., eds., Geomicrobiology: Molecular and Environmental Perspective: Dordrecht, Springer, p. 219-238. https://doi.org/10.1007/978-90-481-9204-5_10

Engel, A.S., Paoletti, M., Beggio, M., Dorigo, L., Pamio, A., Gomiero, T., Furlan, C., Brilli, M., Dreon, A.L., Bertoni, R., and Squartini, A., 2013, Comparative microbial community composition from secondary carbonate (moonmilk) deposits: implications for the Cansiliella servadeii cave hygropetric food web: International Journal of Speleology, v. 42, no. 3, p. 181-192. https://doi.org/10.5038/1827-806X.42.3.2.

Engel, A.S., Porter, M.L., Stern, L.A., Quinlan, S., and Bennett, P.C., 2004b, Bacterial diversity and ecosystem function of filamentous microbial mats from aphotic (cave) sulfidic springs dominated by chemolithoautotrophic "Epsilonproteobacteria": FEMS Microbiology Ecology, v. 51, no. 1, p. 31-53. https://doi.org/10.1016/j.femsec.2004.07.004.

Engel, A.S., Stern, L.A., and Bennett, P.C., 2004a, Microbial contributions to cave formation: New insights into sulfuric acid speleogenesis: Geology, v. 32, p. 369-372. https://doi.org/10.1130/G20288.1.

Estes, E.R., Andeer, P.F., Nordlund, D., Wankel, S.D., and Hansel, C.M., 2017, Biogenic manganese oxides as reservoirs of organic carbon and proteins in terrestrial and marine environments: Geobiology, v. 15, no. 1, p. 158-172. https://doi.org/10.1111/gbi.12195.

Even, H., Carmi, I., Magaritz, M., and Gerson, R., 1986, Timing the transport of water through the upper vadose zone in a karstic system above a cave in Israel: Earth Surface Processes and Landforms, v. 11, p. 181-191. https://doi.org/10.1002/esp.3290110208.

Fairchild, I.J., and Baker, A., 2012, Speleothem Science: From Process to Past Environments: Oxford, UK, Wiley-Blackwell, 432 p. https://doi. org/10.1002/9781444361094.

Farnleitner, A.H., Wilhartitz, I., Ryzinska, G., Kirschner, A.K., Stadler, H., Burtscher, M.M., Hornek, R., Szewzyk, U., Herndl, G., and Mach, R.L., 2005, Bacterial dynamics in spring water of alpine karst aquifers indicates the presence of stable autochthonous microbial endokarst communities: Environmental Microbiology, v. 7, no. 8, p. 1248-59. https://doi.org/10.1111/j.1462-2920.2005.00810.x.

Ferris, F.G., Phoenix, V.R., Fujita, Y., and Smith, R.W., 2003, Kinetics of calcite precipitation induced by ureolytic bacteria at 10 to $20^{\circ} \mathrm{C}$ in artificial groundwater: Geochimica et Cosmochimica Acta, v. 67, p. 1701-1722. https://doi.org/10.1016/S0016-7037(03)00503-9.

Forbes, J.R., 2000, Geochemistry of Carlsbad Cavern pool waters, Guadalupe Mountains, New Mexico: Journal of Cave and Karst Studies, v. 62, no. 2, p. 127-134.

Frost, E.L., Budd, D.A., and Kerans, C., 2013, Syndepositional deformation in a high-relief carbonate platform and its effect on early fluid flow as revealed by dolomite patterns: Journal of Sedimentary Research, v. 82, no. 12, p. 913-932. https://doi.org/10.2110/jsr.2012.74.

Genty, D., Labuhn, I., Hoffmann, G., Danis, P.A., Mestre, O., Bourges, F., Wainer, K., Massault, M., Van Exter, S., Régnier, E., Orengo, P., Falourd, S., and Minster, B., 2014, Rainfall and cave water isotopic relationships in two South-France sites: Geochimica et Cosmochimica Acta, v. 131, p. 323-343. https://doi.org/10.1016/j.gca.2014.01.043.

Giovannoni, S.J., DeLong, E.F., Schmidt, T.M., and Pace, N.R., 1990, Tangential flow filtration and preliminary phylogenetic analysis of marine picoplankton: Applied and Environmental Microbiology, v. 56, p. 2572-2575. https://doi.org/10.1128/AEM.56.8.2572-2575.1990.

Goldscheider, N., Hunkeler, D., and Rossi, P., 2006, Review: Microbial biocenoses in pristine aquifers and an assessment of investigative methods: Hydrogeology Journal, v. 14, no. 6, p. 926-941. https://doi.org/10.1007/s10040-005-0009-9.

Grice, E.A., and Segre, J.A., 2011, The skin microbiome: Nature Reviews Microbiology, v. 9, no. 4, p. 244-253. https://doi.org/10.1038/nrmicro2537.

Griebler, C., and Lueders, T., 2009, Microbial biodiversity in groundwater ecosystems: Freshwater Biology, v. 54, no. 4, p. 649-677. https://doi. org/10.1111/j.1365-2427.2008.02013.x.

Griffin, D.W., Gray, M.A., Lyles, M.B., and Northup, D.E., 2014, The transport of nonindigenous microorganisms into caves by human visitation: A case study at Carlsbad Caverns National Park: Geomicrobiology Journal, v. 31, no. 3, p. 175-185. https://doi.org/10.1080/01490451.2013.815 294. 
Groth, I., Schumann, P., Schütze, B., Augsten, K., and Stackebrandt, E., 2002, Knoellia sinensis gen. nov., sp. nov. and Knoellia subterranea sp. nov., two novel actinobacteria isolated from a cave: International Journal of Systematic and Evolutionary Microbiology, v. 52, p. 77-84. https:// doi.org/10.1099/00207713-52-1-77

Gulden, B, 2020, Worlds longest caves, http://www.caverbob.com/wlong.htm, [accessed July 20, 2020].

Gutierrez, T., Green, D.H., Nichols, P.D., Whitman, W.B., Semple, K.T., and Aitken, M.D., 2013, Polycyclovorans algicola gen. nov., sp. nov., an aromatic-hydrocarbon-degrading marine bacterium found associated with laboratory cultures of marine phytoplankton: Applied and Environmental Microbiology, v. 79, no. 1, p. 205-214. https://doi.org/10.1128/AEM.02833-12.

Hershey, O.S., Kallmeyer, J., Wallace, A., Barton, M.D., and Barton, H.A., 2018, High microbial diversity despite extremely low biomass in a deep karst aquifer: Frontiers in Microbiology, v. 9, p. 2823. https://doi.org/10.3389/fmicb.2018.02823.

Hill, C.A., 1987, Geology of Carlsbad Cavern and Other Caves in the Guadalupe Mountains, New Mexico and Texas: Socorro, New Mexico, New Mexico Bureau of Mines and Mineral Resources, $150 \mathrm{p}$.

Hill, C.A., 1990, Sulfuric acid speleogenesis of Carlsbad Cavern and its relationship to hydrocarbons, Delaware Basin, New Mexico and Texas: American Association of Petroleum Geologists Bulletin, v. 74, p. 1685-1694.

Holmes, A.J., Tujula, N.A., Holley, M., Contos, A., James, J.M., Rogers, P., and Gillings, M.R., 2001, Phylogenetic structure of unusual aquatic microbial formations in Nullarbor cavees, Australia: Environmental Microbiology, v. 3, no. 4, p. 256-264. https://doi.org/10.1046/j.14622920.2001.00187.x.

Hose, L.D., and Macalady, J.L., 2006, Observations from active sulfidic karst systems: is the present the key to understanding Guadalupe Mountain speleogenesis, in Land, L., Lueth, V., Raatz, B., Boston, P.J., and Love, D., eds., Caves and Karst of Southeastern New Mexico, New Mexico Geological Society, p. 185-194.

Hose, L.D., Palmer, A.N., Palmer, M.V., Northup, D.E., Boston, P.J., and DuChene, H.R., 2000, Microbiology and geochemistry in a hydrogen-sulphide-rich karst environment: Chemical Geology, v. 169, p. 399-423. https://doi.org/10.1016/S0009-2541(00)00217-5

Hose, L.D., and Rosales-Lagarde, L., 2017, Sulfur-rich caves of southern Tabasco, Mexico, in Klimchouk, A.B., Palmer, A.N., DeWaele, J., Auler, A.S., and Audra, P., eds., Hypogene Karst Regions and Caves of the World, Springer International Publishing, p. 803-814. https://doi. org/10.1007/978-3-319-53348-3_54

Ikner, L.A., Toomey, R.S., Nolan, G., Neilson, J.W., Pryor, B.M., and Maier, R.M., 2007, Culturable microbial diversity and the impact of tourism in Kartchner Caverns, Arizona: Microbial Ecology, v. 53, no. 1, p. 30-42. https://doi.org/10.1007/s00248-006-9135-8

Ingraham, N.L., Chapman, J.B., and Hess, J.W., 1990, Stable isotopes in cave pool systems: Carlsbad Cavern, New Mexico, U.S.A.: Chemical Geology, v. 86, p. 65-74. https://doi.org/10.1016/0168-9622(90)90006-X.

Irgens, R.L., Gosink, J.J., and Staley, J.T., 1996, Polaromonas vacuolata gen. nov., sp. nov., a psychrophilic, marine, gas vacuolate bacterium from Antarctica: International Journal of Systematic Bacteriology, v. 46, p. 822-826. https://doi.org/10.1099/00207713-46-3-822.

Ivanova, N., Daum, C., Lang, E., Abt, B., Kopitz, M., Saunders, E., Lapidus, A., Lucas, S., Glavina Del Rio, T., Nolan, M., Tice, H., Copeland, A., Cheng, J.F., Chen, F., Bruce, D., Goodwin, L., Pitluck, S., Mavromatis, K., Pati, A., Mikhailova, N., Chen, A., Palaniappan, K., Land, M., Hauser, L., Chang, Y.J., Jeffries, C.D., Detter, J.C., Brettin, T., Rohde, M., Goker, M., Bristow, J., Markowitz, V., Eisen, J.A., Hugenholtz, P., Kyrpides, N.C., and Klenk, H.P., 2010, Complete genome sequence of Haliangium ochraceum type strain (SMP-2): Standards in Genomic Sciences, v. 2, no. 1, p. 96-106. https://doi.org/10.4056/sigs.69.1277.

Jagnow, D.H., 1979, Cavern Development in the Guadalupe Mountains: Columbus, Ohio, Cave Research Foundation, 55 p.

Jagnow, D.H., Hill, C.A., Davis, D.G., DuChene, H.R., Cunningham, K.I., Northup, D.E., and Queen, J.M., 2000, History of sulfuric acid theory of speleogenesis in the Guadalupe Mountains, New Mexico and west Texas: Journal of Cave and Karst Studies, v. 62, no. 2, p. 54-59.

Jang, J., Anderson, E.L., Venterea, R.T., Sadowsky, M.J., Rosen, C.J., Feyereisen, G.W., and Ishii, S., 2019, Denitrifying bacteria active in woodchip bioreactors at low-temperature conditions: Frontiers in Microbiology, v. 10, p. 635. https://doi.org/10.3389/fmicb.2019.00635.

Jones, A.A., and Bennett, P.C., 2017, Mineral Ecology: Surface specific colonization and geochemical drivers of biofilm accumulation, composition, and phylogeny: Frontiers in Microbiology, v. 8, p. 491. https://doi.org/10.3389/fmicb.2017.00491.

Jones, D.S., Schaperdoth, I., and Macalady, J.L., 2016, Biogeography of sulfur-oxidizing Acidithiobacillus populations in extremely acidic cave biofilms: ISEM Journal, v. 10, p. 2879-2891. https://doi.org/10.1038/ismej.2016.74.

Karwautz, C., Kus, G., Stockl, M., Neu, T.R., and Lueders, T., 2018, Microbial megacities fueled by methane oxidation in a mineral spring cave: International Society for Microbial Ecology Journal, v. 12, no. 1, p. 87-100. https://doi.org/10.1038/ismej.2017.146.

Kaufman, A., Bar-Matthews, M., Ayalon, A., and Carmi, I., 2003, The vadose flow above Soreq Cave, Israel: a tritium study of the cave waters: Journal of Hydrology, v. 273, p. 155-163. https://doi.org/10.1016/S0022-1694(02)00394-3.

Kim, B.R., Shin, J., Guevarra, R., Lee, J.H., Kim, D.W., Seol, K.H., Lee, J.H., Kim, H.B., and Isaacson, R., 2017, Deciphering Diversity Indices for a Better Understanding of Microbial Communities: Journal of Microbiology and Biotechnology, v. 27, no. 12, p. 2089-2093. https://doi. org/10.4014/jmb.1709.09027.

Kirkland, D.W., 2014, Role of Hydrogen Sulfide in the Formation of Cave and Karst Phenomena in the Guadalupe Mountains and Western Delaware Basin, New Mexico and Texas, National Cave and Karst Research Institute, $77 \mathrm{p}$.

Kirs, M., Kisand, V., Nelson, C.E., Dudoit, T., and Moravcik, P.S., 2020, Distinct bacterial communities in tropical island aquifers: PLOS One, v. 15 , no. 4, p. e0232265. https://doi.org/10.1371/journal.pone.0232265.

Koch, H., Lucker, S., Albertsen, M., Kitzinger, K., Herbold, C., Spieck, E., Nielsen, P.H., Wagner, M., and Daims, H., 2015, Expanded metabolic versatility of ubiquitous nitrite-oxidizing bacteria from the genus Nitrospira: Proceedings of the National Academy of Sciences of the United States of America, v. 112, no. 36, p. 11371-11376. https://doi.org/10.1073/pnas.1506533112.

Kumaresan, D., Stephenson, J., Doxey, A.C., Bandukwala, H., Brooks, E., Hillebrand-Voiculescu, A., Whiteley, A.S., and Murrell, J.C., 2018, Aerobic proteobacterial methylotrophs in Movile Cave: genomic and metagenomic analyses: Microbiome, v. 6, no. 1, p. 1. https://doi.org/10.1186/ s40168-017-0383-2.

Land, L., and Burger, P., 2008, Rapid recharge events in a karstic aquifer: An example from Lake of the White Roses, Lechuguilla Cave, New Mexico, in 11th Multidisciplinary Conference on Sinkholes and the Engineering and Environmental Impacts of Karst, Tallahassee, Florida, ASCE Geotechnical Special Publication no. 183, p. 396-403 https://doi.org/10.1061/41003(327)37.

Lane, D.J., 1991, 16S/23S rRNA sequencing, in Stackebrandt, E., and Goodfellow, M, eds, Nucleic Acid Techniques in Bacterial Systematics, p. 115-175.

Lavoie, K.H., and Northup, D.E., 2005, Bacteria as indicators of human impact in caves, in Rea, G.T., ed., 17th National Cave and Karst Management Symposium, NICKMS Steering Committee, p. 40-47.

Lavoie, K.H., Winter, A.S., Read, K.J., Hughes, E.M., Spilde, M.N., and Northup, D.E., 2017, Comparison of bacterial communities from lava cave microbial mats to overlying surface soils from Lava Beds National Monument, USA: PLOS One, v. 12, no. 2, p. e0169339. 
Lechleitner, F.A., Dittmar, T., Baldini, J.U.L., Prufer, K.M., and Eglinton, T.I., 2017, Molecular signatures of dissolved organic matter in a tropical karst system: Organic Geochemistry, v. 113, p. 141-149. https://doi.org/10.1016/j.orggeochem.2017.07.015.

Legatzki, A., Ortiz, M., Neilson, J.W., Casavant, R.R., Palmer, M.W., Rasmussen, C., Pryor, B.M., Pierson, L.S., and Maier, R.M., 2012, Factors influencing observed variations in the structure of bacterial communities on calcite formations in Kartchner Caverns, AZ, USA: Geomicrobiology Journal, v. 29, no. 5, p. 422-434. https://doi.org/10.1080/01490451.2011.581326.

Legatzki, A., Ortiz, M., Neilson, J.W., Dominguez, S., Andersen, G.L., Toomey, R.S., Pryor, B.M., Pierson, L.S., and Maier, R.M., 2011, Bacterial and Archaeal community structure of two adjacent calcite speleothems in Kartchner Caverns, Arizona, USA: Geomicrobiology Journal, v. 28, no. 2, p. 99-117. https://doi.org/10.1080/01490451003738465.

Leuko, S., Koskinen, K., Sanna, L., D’Angeli, I.M., De Waele, J., Marcia, P., Moissl-Eichinger, C., and Rettberg, P., 2017, The influence of human exploration on the microbial community structure and ammonia oxidizing potential of the Su Bentu limestone cave in Sardinia, Italy: PLOS One, v. 12, no. 7, p. e0180700. https://doi.org/10.1371/journal.pone.0180700.

Levy, D.B., 2007a, Geochemical trends in selected Lechuguilla Cave pools: Journal of Cave and Karst Studies, v. 69, no. 3, p. 342-350.

Levy, D.B., 2007b, Oxidation-reduction chemistry of Lechuguilla Cave seepage: Journal of Cave and Karst Studies, v. 69, no. 3, p. $351-358$.

Levy, D.B., and Amrhein, C., 2011, Geochemical evolution of hypersaline cave pools, Guadalupe Mountains, New Mexico: Chemical Geology, v. 290, no. 1-2, p. 60-66. https://doi.org/10.1016/j.chemgeo.2011.08.012.

Li, W., Liu, X., and Niu, S., 2019, Differential responses of the acidobacterial community in the topsoil and subsoil to fire disturbance in Pinus tabulaeformis stands: PeerJ - Life \& Environment, v. 7, p. e8047. https://doi.org/10.7717/peerj.8047.

Logan, N.A., and De Vos, P., 2015, Bacillus, in Whitman, W.B., ed., Bergey's Manual of Systematics of Archaea and Bacteria, p. 1-163. https:// doi.org/10.1002/9781118960608.gbm00530.

Loy, A., Beisker, W., and Meier, H., 2005, Diversity of bacteria growing in natural mineral water after bottling: Applied and Environmental Microbiology, v. 71, no. 7, p. 3624-3632. https://doi.org/10.1128/AEM.71.7.3624-3632.2005.

Lu, X., 2018, Distribution and Function of Soil Thaumarchaeota: University of Waterloo, $159 \mathrm{p}$.

Macalady, J.L., Dattagupta, S., Schaperdoth, I., Jones, D.S., Druschel, G.K., and Eastman, D., 2008, Niche differentiation among sulfur-oxidizing bacterial populations in cave waters: International Society for Microbial Ecology Journal, v. 2, no. 6, p. 590-601. https://doi.org/10.1038/ ismej.2008.25.

Macalady, J.L., Jones, D.S., and Lyon, E.H., 2007, Extremely acidic, pendulous cave wall biofilms from the Frasassi cave system, Italy: Environmental Microbiology, v. 9, p. 1402-1414. https://doi.org/10.1111/j.1462-2920.2007.01256.x.

Macalady, J.L., Lyon, E.H., Koffman, B., Albertson, L.K., Meyer, K., Galdenzi, S., and Mariani, S., 2006, Dominant microbial populations in limestone-corroding stream biofilms, Frasassi cave system, Italy: Applied and Environmental Microbiology, v. 72, no. 8, p. 5596-5609.https://doi. org/10.1128/AEM.00715-06.

McDonald, D., Price, M.N., Goodrich, J., Nawrocki, E.P., DeSantis, T.Z., Probst, A., Andersen, G.L., Knight, R., and Hugenholtz, P., 2012, An improved Greengenes taxonomy with explicit ranks for ecological and evolutionary analyses of bacteria and archaea: International Society for Microbial Ecology Journal, v. 6, no. 3, p. 610-618. https://doi.org/10.1038/ismej.2011.139.

McMurdie, P.J., and Holmes, S., 2013, Phyloseq: an R package for reproducible interactive analysis and graphics of microbiome census data: PLOS One, v. 8, no. 4, p. e61217. https://doi.org/10.1371/journal.pone.0061217.

Meisinger, D.B., Zimmermann, J., Ludwig, W., Schleifer, K.H., Wanner, G., Schmid, M., Bennett, P.C., Engel, A.S., and Lee, N.M., 2007, In situ detection of novel Acidobacteria in microbial mats from a chemolithoautotrophically based cave ecosystem (Lower Kane Cave, WY, USA): Environmental Microbiology, v. 9, no. 6, p. 1523-34. https://doi.org/10.1111/j.1462-2920.2007.01271.x.

Melim, L.A., Brehm, A., Rust, G., Shannon, N., and Northup, D.E., 2006, The unknown crust beneath your feet: Cave pool precipitates of Lower Cave, Carlsbad Cavern, New Mexico, in Raatz, W., Land, L., and Boston, P.J., eds., Caves and Karst of Southeastern New Mexico, New Mexico Geological Society Guidebook, 57th Field Conference, p. 38-40.

Melim, L.A., and Scholle, P.A., 2002, Dolomitization of the Capitan Formation forereef facies (Permian, West Texas and New Mexico): Seepage reflux revisited: Sedimentology, v. 49, no. 6, p. 1207-1228. https://doi.org/10.1046/j.1365-3091.2002.00492.x.

Melim, L.A., and Spilde, M.N., 2018, A New Unified Model For Cave Pearls: Insights from cave pearls in Carlsbad Cavern, New Mexico, U.S.A: Journal of Sedimentary Research, v. 88, no. 3, p. 344-364. https://doi.org/10.2110/jsr.2018.21.

Mercier, C., Boyer, F., Bonin, A., and Coissac, E., 2013, SUMATRA and SUMACLUST: fast and exact comparison and clustering of sequences, SeqBio Invited talks, p. 27-29.

Mischel, S.A., Scholz, D., and Spötl, C., 2015, $\delta 180$ values of cave drip water: a promising proxy for the reconstruction of the North Atlantic Oscillation?: Climate Dynamics, v. 45, no. 11-12, p. 3035-3050. https://doi.org/10.1007/s00382-015-2521-5.

Mohr, K.I., 2018, Diversity of Myxobacteria-We only see the tip of the iceberg: Microorganisms, v. 6, no. 3., 23 p. https://doi.org/10.3390/microorganisms6030084.

Momper, L., Jungbluth, S.P., Lee, M.D., and Amend, J.P., 2017, Energy and carbon metabolisms in a deep terrestrial subsurface fluid microbial community: International Society for Microbial Ecology Journal, v. 11, no. 10, p. 2319-2333. https://doi.org/10.1038/ismej.2017.94.

Naether, A., Foesel, B.U., Naegele, V., Wust, P.K., Weinert, J., Bonkowski, M., et al., 2012, Environmental factors affect Acidobacterial communities below the subgroup level in grassland and forest soils: Applied and Environmental Microbiology, v. 78, no. 20, p. 7398-7406. https://doi. org/10.1128/AEM.01325-12

NCBI, 2020, Nucleotide, https://www.ncbi.nlm.nih.gov/nucleotide?cmd=search [Accessed July 10, 2020].

Northup, D.E., Barnes, S.M., Yu, L.E., Spilde, M.N., Scheble, R.T., Dano, K.E., Crossey, L.J., Connolly, C.A., Boston, P.J., Natvig, D.O., and Dahm, C.N., 2003, Diverse microbial communities inhabiting ferromanganese deposits in Lechuguilla and Spider Caves: Environmental Microbiology, v. 5, p. 1071-1086. https://doi.org/10.1046/j.1462-2920.2003.00500.x.

Northup, D.E., Snider, J.R., Spilde, M.N., Porter, M.L., van de Kamp, J.L., Boston, P.J., Nyberg, A.M., and Bargar, J.R., 2010, Diversity of rock varnish bacterial communities from Black Canyon, New Mexico, Journal of Geophysical Research, v. 115, p. G02007, doi:10.1029/ 2009JG001107

Ortiz, M., Legatzki, A., Neilson, J.W., Fryslie, B., Nelson, W.M., Wing, R.A., Soderlund, C.A., Pryor, B.M., and Maier, R.M., 2014, Making a living while starving in the dark: metagenomic insights into the energy dynamics of a carbonate cave: International Society for Microbial Ecology Journal, v. 8, p. 478-491. https://doi.org/10.1038/ismej.2013.159.

Ortiz, M., Neilson, J.W., Nelson, W.M., Legatzki, A., Byrne, A., Yu, Y., Wing, R.A., Soderlund, C.A., Pryor, B.M., Pierson, L.S., 3rd, and Maier, R.M., 2013, Profiling bacterial diversity and taxonomic composition on speleothem surfaces in Kartchner Caverns, AZ: Microbial Ecology, v. 65, no. 2, p. 371-383. https://doi.org/10.1007/s00248-012-0143-6. 
Oster, J.L., Montañez, I.P., and Kelley, N.P., 2012, Response of a modern cave system to large seasonal precipitation variability: Geochimica et Cosmochimica Acta, v. 91, p. 92-108. https://doi.org/10.1016/j.gca.2012.05.027.

Palmer, A.N., 2006, Support for a sulfuric acid origin for caves in the Guadalupe Mountains, New Mexico, in Land, L., Lueth, V., Raatz, B., Boston, P.J., and Love, D., eds., Caves and Karst of Southeastern New Mexico, New Mexico Geological Society, p. $195-202$.

Palmer, A.N., 2007, Cave Geology: Dayton, Ohio, Cave Books, 454 p.

Palmer, A.N., and Palmer, M.V., 2000, Hydrochemical interpretation of cave patterns in the Guadalupe Mountains, New Mexico: Journal of Cave and Karst Studies, v. 62, no. 2, p. 91-108.

Palmer, M., and Palmer, A., 2012, Petrographic and isotopic evidence for late-stage processes in sulfuric acid caves of the Guadalupe Mountains, New Mexico, USA: International Journal of Speleology, v. 41, no. 2, p. 231-250. https://doi.org/10.5038/1827-806X.41.2.10.

Pagnier, I., Raoult, D., and La Scola, B., 2011, Isolation and characterization of Reyranella massiliensis gen. nov., sp. nov. from freshwater samples by using an amoeba co-culture procedure: International Journal of Systematic and Evolutionary Microbiology, v. 61, no. Pt 9, p. 2151-2154. https://doi.org/10.1099/ijs.0.025775-0.

Parro, V., and Moreno-Paz, M., 2004, Nitrogen fixation in acidophile iron-oxidizing bacteria: the nif regulon of Leptospirillium ferrooxidans: Research in Microbiology, v. 155, p. 703-709. https://doi.org/10.1016/j.resmic.2004.05.010.

Pichinoty, F., de Barjac, H., Mandel, M., and Asselineau, J., 1983, Description of Bacillus azotoformans sp. nov.: International Journal of Systematic Bacteriology, v. 33, p. 660-662. https://doi.org/10.1099/00207713-33-3-660.

Plese, B., Pojskic, N., Ozimec, R., Mazija, M., Cetkovic, H., and Lukic-Bilela, L., 2016, Molecular characterization of aquatic bacterial communities in Dinaric Range caves: Water Environment Research, v. 88, p. 617-630. https://doi.org/10.2175/106143016X14609975746488.

Polyak, V.J., Asmerom, Y., Burns, S.J., and Lachniet, M.S., 2012, Climatic backdrop to the terminal Pleistocene extinction of North American mammals: Geology, v. 40, no. 11, p. 1023-1026. https://doi.org/10.1130/G33226.1.

Polyak, V.J., McIntosh, W.C., Güven, N., and Provencio, P., 1998, Age and origin of Carlsbad Cavern and related caves from ${ }^{40} \mathrm{Ar} /{ }^{39} \mathrm{Ar}$ of alunite: Science, v. 279, p. 1919-1922. https://doi.org/10.1126/science.279.5358.1919.

Porca, E., Jurado, V., Zgur-Bertok, D., Saiz-Jimenez, C., and Pasic, L., 2012, Comparative analysis of yellow microbial communities growing on the walls of geographically distinct caves indicates a common core of microorganisms involved in their formation: FEMS Microbiology Ecology, v. 81, no. 1, p. 255-266. https://doi.org/10.1111/j.1574-6941.2012.01383.x.

Porter, M.L., Engel, A.S., Kane, T.C., and Kinkle, B.K., 2009, Productivity-diversity relationships from chemolithoautotrophically based sulfidic karst systems: International Journal of Speleology, v. 38, p. 27-40. https://doi.org/10.5038/1827-806X.38.1.4.

Pronk, M., Goldscheider, N., and Zopfi, J., 2009, Microbial communities in karst groundwater and their potential use for biomonitoring: Hydrogeology Journal, v. 17, no. 1, p. 37-48. https://doi.org/10.1007/s10040-008-0350-x.

R Development Core Team, 2012, R: A language and environment for statistical computing. Vienna: R Foundation for Statistical Computing. Available: http://www.R-project.org

Rivas-Marin, E., and Devos, D.P., 2018, The paradigms they are a-changin': Past, present and future of PVC bacteria research: Antonie Van Leeuwenhoek, v. 111, no. 6, p. 785-799. https://doi.org/10.1007/s10482-017-0962-z.

Rusterholtz, K.J., and Mallory, L.M., 1994, Density, activity, and diversity of bacteria indigenous to a karst aquifer: Microbial Ecology, v. 28, p. 79-99. https://doi.org/10.1007/BF00170249

Sarbu, S.M., Kane, T.C., and Kinkle, B.K., 1996, A Chemoautotrophically based cave ecosystem: Science, v. 272, p. 1953-1955. https://doi. org/10.1126/science. 272.5270 .1953$.

Sauro, F., Cappelletti, M., Ghezzi, D., Columbu, A., Hong, P.Y., Zowawi, H.M., Carbone, C., Piccini, L., Vergara, F., Zannoni, D., and De Waele, J., 2018, Microbial diversity and biosignatures of amorphous silica deposits in orthoquartzite caves: Scientific Reports, v. 8, no. 1, p. 17569. https://doi.org/10.1038/s41598-018-35532-y.

Savio, D., Stadler, P., Reischer, G.H., Demeter, K., Linke, R.B., Blaschke, A.P., Mach, R.L., Kirschner, A.K.T., Stadler, H., and Farnleitner, A.H., 2019, Spring water of an alpine karst aquifer is dominated by a taxonomically stable but discharge-responsive bacterial community: Frontiers in Microbiology, v. 10, p. 28. https://doi.org/10.3389/fmicb.2019.00028.

Savio, D., Stadler, P., Reischer, G.H., Kirschner, A.K.T., Demeter, K., Linke, R., et al., 2018, Opening the black box of spring water microbiology from alpine karst aquifers to support proactive drinking water resource management: WIREs Water, v. 5, no. 3, p. e1282. https://doi. org/10.1002/wat2.1282.

Shabarova, T., and Pernthaler, J., 2010, Karst pools in subsurface environments: Collectors of microbial diversity or temporary residence between habitat types: Environmental Microbiology, v. 12, p. 1061-1074. https://doi.org/10.1111/j.1462-2920.2009.02151.x.

Shabarova, T., Villiger, J., Morenkov, O., Niggemann, J., Dittmar, T., and Pernthaler, J., 2014, Bacterial community structure and dissolved organic matter in repeatedly flooded subsurface karst water pools: FEMS Microbiology Ecology, v. 89, no. 1, p. 111-26. https://doi.org/10.1111/15746941.12339.

Shabarova, T., Widmer, F., and Pernthaler, J., 2013, Mass effects meet species sorting: transformations of microbial assemblages in epiphreatic subsurface karst water pools: Environmental Microbiology, v. 15, no. 9, p. 2476-2488. https://doi.org/10.1111/1462-2920.12124.

Shen, Y., Chapelle, F.H., Strom, E.W., and Benner, R., 2015, Origins and bioavailability of dissolved organic matter in groundwater: Biogeochemistry, v. 122, no. 1, p. 61-78. https://doi.org/10.1007/s10533-014-0029-4.

Simon, K.S., Pipan, T., and Culver, D.C., 2007, A conceptual model of the flow and distribution of organic carbon in caves: Journal of Cave and Karst Studies, v. 69, p. 279-284.

Spilde, M.N., Northup, D.E., Boston, P.J., Schelble, R.T., Dano, K.E., Crossey, L.J., and Dahm, C.N., 2005, Geomicrobiology of cave ferromanganese deposits; a field and laboratory investigation: Geomicrobiology Journal, v. 22, p. 99-116. https://doi.org/10.1080/01490450590945889.

Spötl, C., Fairchild, I.J., and Tooth, A.F., 2005, Cave air control on dripwater geochemistry, Obir Caves (Austria): Implications for speleothem deposition in dynamically ventilated caves: Geochimica et Cosmochimica Acta, v. 69, p. 2451-2468. https://doi.org/10.1016/j.gca.2004.12.009.

Stackebrandt, E., Cummins, C.S., and Johnson, J.L., 2006, Family Propionibacteriaceae: The Genus Propionibacterium, in Dworkin, M., Falkow, S., Rosenberg, E., Schleifer, K.H., and Stackebrandt, E., eds., The Prokaryotes: New York, NY, Springer, p. 400-418. https://doi. org/10.1007/0-387-30743-5_19.

Swart, R., Riedel, K.-H., and Britz, T., 1998, Optimized standard conditions for determination of nitrate reduction in Propionibacteria: Lait, v. 78, p. 217-226. https://doi.org/10.1051/Lait:1998224.

Tetu, S.G., Breakwell, K., Elbourne, L.D., Holmes, A.J., Gillings, M.R., and Paulsen, I.T., 2013, Life in the dark: metagenomic evidence that a microbial slime community is driven by inorganic nitrogen metabolism: International Society For Microbial Ecology Journal, v. 7, no. 6, p. 1227-1236. https://doi.org/10.1038/ismej.2013.14. 
Thompson, B., Richardson, D., Vangundy, R., and Cahoon, A.B., 2019, Metabarcoding comparison of prokaryotic microbiomes from Appalachian karst caves to surface soils in southwest Virginia, USA: Journal of Cave and Karst Studies, p. 244-253. https://doi.org/10.4311/2019MB0112

Thompson, H.F., Lesaulnier, C., Pelikan, C., and Gutierrez, T., 2018, Visualisation of the obligate hydrocarbonoclastic bacteria Polycyclovorans algicola and Algiphilus aromaticivorans in co-cultures with micro-algae by CARD-FISH: Journal of Microbiological Methods, v. 152, p. 73-79. https://doi.org/10.1016/j.mimet.2018.07.016.

Tomczyk-Żak, K., and Zielenkiewicz, U., 2015, Microbial diversity in caves: Geomicrobiology Journal, v. 33, no. 1, p. 20-38. https://doi.org/10.108 0/01490451.2014.1003341.

Tredici, S.M., Buccolieri, A., Tanini, L., Calcagnile, M., Manno, D., and Alifano, P., 2018, Calcite-forming Bacillus licheniformis thriving on underwater speleothems of a hydrothermal cave: Geomicrobiology Journal, v. 35, no. 9, p. 804-817. https://doi.org/10.1080/01490451.2018.147662 6.

Turin, H.J., and Plummer, M.A., 1995, Tritium in Lechuguilla Cave pool water: Implications for recharge processes: Geological society of America Abstracts with Programs, v. 27, p. 95.

Turin, H.J., and Plummer, M.A., 2000, Lechuguilla Cave pool chemistry, 1986-1999: Journal of Cave and Karst Studies, v. 62, p. 135-143.

Turin, H.J., and Plummer, M.A., 2001, Isotope profiles from three deep western U.S. caves: Insights into arid-region vadose-zone processes: Geological Society of America, Abstracts with Program, v. 33, p. A-110.

Turin, H.J., Plummer, M.A., Phillips, F.M., and Thompson, M.L., 2001, Vadose-zone infiltration velocities: Evidence from Lechuguilla cave pool radioisotopes: Geological Society of America Abstracts with Programs, v. 33, p. 60.

Tyson, G.W., Lo, I., Baker, B.J., Allen, E.E., Hugenholtz, P., and Banfield, J.F., 2005, Genome-directed isolation of the key nitrogen fixer Leptospirillum ferrodiazotrophum sp. nov. from an acidophilic microbial community: Applied and Environmental Microbiology, v. 71, no. 10, p. 6319-6324. https://doi.org/10.1128/AEM.71.10.6319-6324.2005.

van der Heijde, P.K.M., Kolm, K.E., Dawson, H.E., and Brooke, M., 1997, Determining Water Infiltration Routes from Structures Located Above Carlsbad Cavern, Carlsbad Caverns National Park, Carlsbad, New Mexico: International Ground Water Modeling Center, Colorado School of Mines, $90 \mathrm{p}$.

Vimercati, L., Darcy, J.L., and Schmidt, S.K., 2019, The disappearing periglacial ecosystem atop Mt. Kilimanjaro supports both cosmopolitan and endemic microbial communities: Scientific Reports, v. 9, no. 1, p. 10676. https://doi.org/10.1038/s41598-019-46521-0.

Wang, Z., Chang, X., Yang, X., Pan, L., and Dai, J., 2014, Draft genome sequence of Polaromonas glacialis strain R3-9, a psychrotolerant bacterium isolated from arctic glacial foreland: Genome Announcements, v. 2, no. 4, p. e00695-14. https://doi.org/10.1128/genomeA.00695-14.

Wegner, C.-E., Gaspar, M., Geesink, P., Herrmann, M., Marz, M., and Küsel, K., 2019, Biogeochemical regimes in shallow aquifers reflect the metabolic coupling of the elements nitrogen, sulfur, and carbon: Applied and Environmental Microbiology, v. 85, p. e02346-18. https://doi. org/10.1128/AEM.00502-19.

Wickham, H., 2009, ggplot2: Elegant Graphics for Data Analysis: New York, NY, Springer, 212 p. https://doi.org/10.1007/978-0-387-98141-3.

Williams, P.W., 1983, The role of the subcutaneous zone in karst hydrology: Journal of Hydrology, v. 61, p. 45-67. https://doi.org/10.1016/00221694(83)90234-2.

Williams, P.W., and Fowler, A., 2002, Relationship between oxygen isotopes in rainfall, cave percolation waters and speleothem calcite at Waitomo, New Zealand: Journal of Hydrology (New Zealand), v. 41, p. 53-70.

Wu, Y., Tan, L., Liu, W., Wang, B., Wang, J., Cai, Y., and Lin, X., 2015, Profiling bacterial diversity in a limestone cave of the western Loess Plateau of China: Frontiers in Microbiology, v. 6, p. 244. https://doi.org/10.3389/fmicb.2015.00244.

Yasir, M., 2018, Analysis of bacterial communities and characterization of antimicrobial strains from cave microbiota: Brazilian Journal Microbiology, v. 49, no. 2, p. 248-257. https://doi.org/10.1016/j.bjm.2017.08.005.

Yousuf, J., Thajudeen, J., P.A, Aeesa., Joseph, A., Divya, P.S, Varghese, A., and Mohamed Hatha, A.A, 2020, Diversity and activity of culturable nitrogen fixing heterotrophic bacteria from estuarine and coastal environments of Southeastern Arabian Sea (SEAS): Regional Studies in Marine Science, v. 33, p. 100973. https://doi.org/10.1016/j.rsma.2019.100973.

Yun, Y., Wang, H., Man, B., Xiang, X., Zhou, J., Qiu, X., Duan, Y., and Engel, A.S., 2016, The Relationship between pH and bacterial communities in a single karst ecosystem and its implication for soil acidification: Frontiers in Microbiology, v. 7, p. 1955. https://doi.org/10.3389/ fmicb.2016.01955.

Yun, Y., Xiang, X., Wang, H., Man, B., Gong, L., Liu, Q., Dong, Q., and Wang, R., 2015, Five-year monitoring of bacterial communities in dripping water from the Heshang Cave in Central China: Implication for Paleoclimate Reconstruction and Ecological Functions: Geomicrobiology Journal, v. 33, no. 7, p. 1-11. https://doi.org/10.1080/01490451.2015.1062062.

Zhou, J., Gu, Y., Zou, C., and Mo, M., 2007, Phylogenetic diversity of bacteria in an earth-cave in Guizhou Province, Southwest of China: Journal of Microbiology, v. 45, p. 105-112.

Zimmermann, J., Gonzalez, J.M., and Saiz-Jimenez, C., 2006, Epilithic biofilms in Saint Callixtus Catacombs (Rome) harbour a broad spectrum of Acidobacteria: Antonie Van Leeuwenhoek, v. 89, no. 1, p. 203-208. https://doi.org/10.1007/s10482-005-9020-3.

Zimmermann, J., Gonzalez, J.M., Saiz-Jimenez, C., and Ludwig, W., 2005, Detection and phylogenetic relationships of highly diverse uncultured acidobacterial communities in Altamira Cave using 23S rRNA sequence analyses: Geomicrobiology Journal, v. 22, no. 7-8, p. 379-388. https://doi.org/10.1080/01490450500248986. 